\title{
CONTRIBUCIÓN A LA FLORA VASCULAR DE LA REPÚBLICA ARGENTINA: FAMILIA ERICACEAE
}

\author{
Sebastián Teillier ${ }^{1}$, Leonardo D. Amarilla ${ }^{2,3}$ \& Ana M. Anton²
}

\begin{abstract}
${ }^{1}$ Universidad Central de Chile, Escuela de Arquitectura y Paisaje, Santa Isabel 1186, Santiago de Chile, Chile. ${ }^{2}$ Instituto Multidisciplinario de Biología Vegetal (CONICET-UNC), Casilla de Correo 495, 5000 Córdoba, Argentina; anton@imbiv.unc.edu.ar (autor corresponsal).

${ }^{3}$ Facultad de Ciencias Forestales (UNSE) y FCEF y Nat (UNC).
\end{abstract}

\begin{abstract}
Teillier, S.; L. D. Amarilla \& A. M. Anton. 2019. Contribution to the Vascular Flora of Argentina: Family Ericaceae. Darwiniana, nueva serie 7(1): 68-92.

As a preview of the publication of the volume that involves the Ericaceae of Argentina, a treatment of the family in this country is presented. Six genera, 18 species, and two varieties inhabit in Argentina. Most of the genera (Empetrum, Gayloussacia, Lebetanthus, and Vaccinium) have a single species in the country, being two for Agarista, and 12 for Gaultheria; two varieties are recognized in Gaultheria pumila, totalizing 20 taxa, the majority of which are endemic to. The binomial Gautheria myrsinoides is proposed as a substitute for Pernettya prostrata and lectotypes are designated for Gaultheria florida, Gaultheria salicifolia, Pernettya breviflora, Pernettya elegans, Pernettya litoralis, Pernettya melanocarpa and Pernettya minima. This article also includes dichotomous keys, one to recognize the genera present in Argentina and the other to identify the species within each genus. Observations in relevant cases, select studied material, geographic distribution, habitat, and illustrations for three species are included.
\end{abstract}

Keywords. Argentinean flora; Ericaceae; floristics; geographic distribution; status; vernacle names.

Resumen. Teillier, S.; L. D. Amarilla \& A. M. Anton. 2019. Contribución a la Flora Vascular de la República Argentina: Familia Ericaceae. Darwiniana, nueva serie 7(1): 68-92.

Como adelanto de la publicación del volumen que involucra a las Ericaceae de Argentina, se presenta el tratamiento de la familia para el país. Seis géneros, 18 especies y dos variedades habitan en la Argentina. La mayoría de los géneros (Empetrum, Gayloussacia, Lebetanthus y Vaccinium) cuentan con una única especie en el país, siendo dos para Agarista y 12 para Gaultheria; se reconocen dos variedades en Gaultheria pumila, totalizando así 20 taxones, en su gran mayoría endémicos. Se propone el binomio Gaultheria myrsinoides para sustituir a Pernettya prostrata y se designan lectotipos para Gaultheria florida, Gaultheria salicifolia, Pernettya breviflora, Pernettya elegans, Pernettya litoralis, Pernettya melanocarpa y Pernettya minima. Este artículo incluye, además, claves dicotómicas, una de ellas para reconocer a los géneros de la Argentina y otra para identificar las especies de cada género. Se incluyen observaciones en los casos pertinentes, material estudiado selecto, distribución geográfica, hábitat e ilustraciones de todas las especies.

Palabras clave. Distribución geográfica; Ericaceae; Flora Argentina; florística; nombres vulgares; status. 


\section{INTRODUCCIÓN}

Ericaceae tiene la particularidad de haber despertado y sostenido -desde tiempo atrás y hasta la fecha- el interés de destacados especialistas quienes, desde puntos de vista y metodologías diferentes, contribuyeron a conocer sus atributos. Por esta circunstancia, la información que existe es sólida y variada, tal como se percibe en el tratamiento integral que aparece en la serie editada por Klaus Kubitski sobre las familias y los géneros de las plantas vasculares (Stevens \& al. 2004 y trabajos allí citados). En lo que atañe a nuestra región, botánicos como Reiche (1905), Kausel (1949), Sleumer (1934, 1935, 1951, 1959, 1985), Sleumer \& Hermann (1999), Cambi \& Hermann (1989), Hermann \& Cambi (1992), Judd \& Hermann (1990), efectuaron estudios en especies nativas mientras que otros autores (Cabrera, 1983; Sleumer \& Hermann, 1999) en sendas contribuciones florísticas, relevaron los taxones que habitan en la Patagonia argentina y en la provincia de Jujuy.

Cabe señalar que, con frecuencia, se utiliza en descripciones el término ericoide aludiendo a las características que exhiben representantes del género Erica L. tanto por su hábito como por sus hojas muy angostas, generalmente cortas y aproximadas.

Algunos géneros exóticos -en particular Erica ("brezos"), Rhododendron L. ("azaleas") y Arbutus L. se cultivan como ornamentales. En América del Norte -y más recientemente en Sudamérica, particularmente en Perú, Chile y la Argentina- se cultivan varias especies y numerosos híbridos de Vaccinium L. conocidos como "blueberries", "cranberries" o "arándanos", los que son apreciados por sus frutos comestibles y por sus propiedades vitamínicas y antioxidantes.

La familia es también interesante desde el punto de vista fitoquímico por su producción de sustancias tóxicas -en particular las andromedotoxinas- y alelopáticas. A la par, Gaultheria procumbens $\mathrm{L}$. es la fuente original del conocido "aceite de Gaultheria" ("wintergreen oil").

En conjunto, las Ericaceae se caracterizan por albergar micorrizas ericoides. Read (1996) cita registros de este tipo de simbiosis en varias familias entre las que se encuentran Empetraceae, Epacridaceae, Ericaceae, Prionotaceae y Vacciniaceae, todas ellas actualmente congregadas en Ericaceae. Están restringidas a suelos pobres en nutrientes, tanto en ecosistemas con humedad o aridez extrema, siendo la función primaria de la simbiosis la provisión de nitrógeno al hospedante. También se han registrado en Ericaceae -aunque en menor medida-, otros tipos de asociaciones: micorrizas arbutoides, endófitos septados oscuros y hongos ectomicorrícicos y se encuentra en discusión si existen o no casos de micorrizas arbusculares (Urcelay, 2002).

\section{MATERIALES Y MÉTODOS}

Se realizó una exhaustiva revisión del material bibliográfico vinculado con el tratamiento de la familia sea en obras de conjunto (Stevens \& al., 2004) o en contribuciones florísticas, en especial las relacionadas con el territorio en cuestión (Cabrera, 1983; Sleumer \& Hermann, 1999), pero también de otras regiones habida cuenta de que algunos géneros tienen distribución disyunta.

Se revisaron particularmente las propuestas de Reiche (1905), Sleumer (1935, 1985) y Kausel (1949) y se tuvo acceso a material original existente en el herbario del Museo Nacional de Historia Natural de Santiago de Chile (SGO) y en el herbario del Instituto Darwinion (Leucothoë paraguayensis var. calva).

Dos bases de datos [Tropicos (http://www. tropicos.org) y JSTOR (https://www.plants. jstor.org)] a la par del Index Herbariorum (Thiers, 2018) fueron consistentemente consultadas, en particular para establecer sinonimias taxonómicas o nomenclaturales. El acceso a imágenes digitales nos permitió observar materiales originales estudiados por especialistas quienes dejaron su impronta en observaciones críticas. Para establecer la distribución geográfica de los taxones se contó con los beneficios de DOCUMENTA FLORAE AUSTRALIS, además, se tuvo acceso a las colecciones CORD y SI y a imágenes de colecciones de BAB y BBB. 


\section{RESULTADOS}

\section{TRATAMIENTO TAXONÓMICO}

Familia ERICACEAE Juss., Gen. Pl.: 159. 1789, nom. cons. TIPO: Erica L.

Arbolitos, arbustos o subarbustos, en general siempreverdes, monoclinos (con flores perfectas), siendo común la autogamia, dioicos o eventualmente polígamos (con flores imperfectas), ginodioecia registrada en Gaultheria y en la tribu Styphelieae. En algunos casos las especies son funcionalmente dioicas debido a la existencia de protandria. Hojas alternas, simples, coriáceas, sin estípulas. Flores actinomorfas o apenas zigomorfas, pequeñas, blanquecinas, perladas, rosáceas 0 rojizas, agrupadas en racimos o panículas laxas axilares o terminales, a veces con el eje abreviado y en fascículos, o solitarias y péndulas en las axilas de las hojas superiores; cáliz persistente con 4-5 sépalos unidos en la base (4-)5-partido con lóbulos imbricados o constituido por 3 piezas imbricadas en Vaccinium; corola urceolada a campanulada, caduca con (4-)5 lóbulos breves e imbricados; androceo con 5-10 estambres, reducidos a estaminodios en las flores pistiladas, filamentos libres, insertos en la base de la corola, anteras con tecas frecuentemente provistas de apéndices dorsales bifurcados, dehiscentes por poros o pequeñas escisiones apicales o laterales; polen generalmente en tétrades; nectario (8-)10-lobulado o apenas notable; gineceo 4-5-carpelar, ovario súpero o ínfero en algunos representantes de Vaccinioideae, incompletamente 5-10-locular, placentación axilar o parietal; estilo único, tan largo como la corola; estigma capitado, usualmente 5-lobado. Fruto capsular y dehiscente o carnoso (baya); en Gaultheria, se encuentran bayas o cápsulas cubiertas por el cáliz acrescente y carnoso. Semillas 1-10-numerosas, pequeñas, elipsoides, ovoides o fusiformes; embrión recto, endosperma abundante, carnoso.

Ericaceae está constituida por alrededor de 120 géneros y 4100 especies ampliamente distribuidas en el mundo, las que se congregan en seis subfamilias; tres de ellas -Vaccinoideae, Styphelioideae y Ericoideae- están representadas en la Argentina por siete géneros y 18 especies (20 taxones).

\section{Clave de los géneros de Ericaceae presentes en Argentina}

1. Ovario súpero

1. Ovario ínfero

2(1). Flores 4- ó 5-meras, gamosépalas y gamopétalas. Estambres 5 ó 10. Fruto drupáceo e indehiscente o capsular y dehiscente. Flores generalmente en racimos axilares, raro solitarias

2. Flores 3-meras, el perianto formado por 2 verticilos de 3 piezas imbricadas. Estambres 3, reducidos a estaminodios en las flores pistiladas. Anteras sin apéndices apicales con dehiscencia longitudinal. Fruto drupáceo (nuculanio), epicarpo y mesocarpo carnosos y endocarpo leñoso con 7-9 pirenos. Flores solitarias en las axilas de las hojas superiores. Plantas generalmente dioicas, raro polígamas o monoclinas. Patagonia, islas Malvinas

Empetrum

3(2). Anteras con 2 pares de aristas (apéndices dorsales bifurcados). Fruto una baya o una cápsula rodeada por el cáliz acrescente y carnoso. Flores generalmente imperfectas (plantas dioicas o polígamas), excepto Gaultheria erecta y G. nubigena que son monoclinas (flores perfectas) Gaultheria

3. Anteras sin aristas. Fruto capsular y dehiscente, con el cáliz perdurando o no en la base de la flor pero ni acrescente ni carnoso. Flores perfectas (plantas monoclinas)

4(3). Estambres 10. Flores agrupadas en racimos axilares laxos en el extremo de las ramas. Bractéolas 2 (4). Corola 6,5-10. En Argentina, en Salta y Misiones Agarista

4. Estambres 5. Flores solitarias, péndulas, axilares, acompañadas de (8)-10-18 bractéolas imbricadas. Corola 4-6. Santa Cruz y Tierra del Fuego Lebetanthus

5(1). Ovario 10-locular. Fruto drupáceo con 10 pirenos, más o menos seco a la madurez Gaylussacia

5. Ovario 4-5-locular. Baya claramente 5-locular, carnosa a la madurez, negro-azulada, coronada por los lóbulos del cáliz Vaccinium 
Agarista D. Don ex G. Don., Gen. Hist. 3: 788, 837. 1834. ESPECIE TIPO: Agarista nummularia (Cham. \& Schltdl.) G. Don (=Andromeda nummularia Cham. \& Schltdl.), lectotipo designado por W. S. Judd, J. Arnold Arbor. 65: 274. 1984.

Arbustos o arbolitos generalmente glabros; corteza rugosa, longitudinalmente surcada; médula generalmente tabicada, septos regular o irregularmente dispuestos, o poco evidentes en A. paraguayensis. Hojas coriáceas, alternas, pecioladas, aserradas o enteras, los bordes irregularmente ondulados y retorcidos en A. boliviensis. Inflorescencia en racimos axilares desarrollados en ramas de la estación previa, abiertas, la flor terminal ausente. Flores actinomorfas, perfectas, subtendidas por una bráctea, sobre pedicelos que llevan un par de bractéolas en la mitad inferior, péndulas cuando jóvenes, 5-meras, fragantes; cáliz persistente con 5 sépalos imbricados y apenas connatos en la base; corola simpétala, caduca, cilíndrica, tendiendo o no a urceolada, blanca o con tintes rosados o rojizos; androceo con 10 estambres dispuestos en 2 verticilos, incluidos en la corola e insertos en su base, filamentos delgados y provistos de largos pelos unicelulares en su porción proximal, anteras introrsas con dehiscencia poricida; gineceo súpero, placentación axilar, con una columela central donde se ubican las placentas en posición subapical o central (carácter que se expresa mejor en el fruto). Fruto cápsula loculicida 5-valvada, erecta por curvatura del pedicelo a la madurez. Semillas pequeñas, comprimidas, estrechamente aladas.

El género se divide en dos secciones naturales morfológicamente diferentes. Agarista sect. Agauria (DC.) Judd. cuenta con una única especie -A. salicifolia (Lam.) G. Don-, que habita en África tropical incluyendo Madagascar y las islas Mascareñas. Por su amplia distribución geográfica y la gran variabilidad que muestra, algunos especialistas han propuesto categorías infraespecíficas no siempre aceptadas. Agarista sect. Agarista congrega 29 especies (34 taxones) exclusivamente americanas, y está especialmente diversificada en Sudamérica, en particular en el SE de Brasil. En la Argentina habitan dos especies alopátricas.

\section{Clave de las especies de Agarista en la Argentina}

1. Cápsulas con placentación $+/$ - subapical. Semillas de 2-2,5 mm. Corola blanco perlado, tubuloso-urceolada ca. $8 \mathrm{~mm}$, glabra. Médula tabicada, los septos irregularmente dispuestos. Hojas glabras en la cara abaxial, margen irregularmente ondulado y crenulado. Bolivia y NO de Argentina (Jujuy) A. boliviensis 1. Cápsulas con placentación +/- central. Semillas de 0,9-1,8 mm. Corola rojiza, cilíndrica, apenas pubescente. Médula prácticamente hueca, raras veces con septos dispersos y finos. Hojas densamente pubescentes en la cara abaxial (por excepción la pubescencia limitada a la nervadura media), margen entero o apenas ondulado. Centro-este de Paraguay y NE de Argentina (Misiones) A. paraguayensis

Agarista boliviensis (Sleumer) Judd, J. Arnold Arbor. 65: 333. 1984. Leucothoë boliviensis Sleumer, Notizbl. Bot. Gart. Berlin-Dahlem 12(112): 131. 1934. TIPO: Bolivia. Santa Cruz, Tal von Comarapa, 2000 m, blühend und fruchtend am, 26 X 1928, J. Steinbach 8568 (holotipo $\mathrm{B}^{\dagger}$; lectotipo LIL 57450! aquí designado; isolectotipos BM cb 000906616!, F cb 0055439F!, E cb 00326869!, K cb 000494460!, NY cb 00010139!, S cb 05-4188!, U cb 0001716!, UC cb 394830!, US fragmento ex B).
Arbustos o arbolitos de 2-7 m de altura con tronco de hasta $20 \mathrm{~cm}$ diámetro con corteza rugosa. Ramas jóvenes glabras. Hojas con lámina ovado-lanceolada, de 4-7 × 1,5-3 cm, aguda en el ápice, bordes ondulado-crenulado, coriácea, glabra en ambas caras, lustrosa en la haz y más pálida en el envés, donde las nervaduras son más conspicuas; pecíolos de 6-12 mm. Inflorescencia en racimos axilares laxos en la parte superior de las ramas, de 3-7 cm. Flores largamente pediceladas, pedicelos de $5-10 \mathrm{~cm}$; cáliz muy 
breve, 5-mero, pubescencia abaxial; corola color blanco perlado, tubuloso-urceolada, tubo de $8-10 \mathrm{~mm}$ y limbo breve, 5-dentado. Fruto capsular, a la madurez subgloboso a ovoide, de 3,5-4,5 × 5-6,5 mm; placenta subapical. Semillas de $2-2,5 \mathrm{~mm}$.

Iconografía. Cabrera, A. L. 1983. 13(8): 9, fig. 4.

Distribución y hábitat. Centro-sur de Bolivia, poco frecuente en el noroeste argentino, en regiones montañosas entre los 1200-2500 m s.m. Se la ha registrado en pastizales serranos en Salta y en el bosque de Alnus acuminata Kunth ("aliso"), en Jujuy. Florece en noviembre (septiembre/octubre).

\section{Material representativo examinado}

ARGENTINA. Jujuy. Depto. Palpalá: Sierra de Zapla, mina 9 de octubre, subida a la antena, Cabrera et al. 30549 (SI). Salta. Depto. Anta: Parque Nacional El Rey, pastizal serrano, Chalukian 1002 (SI).

Agarista paraguayensis (Sleumer) Judd, J. Arnold Arbor. 65: 307. 1984. Leucothoë paraguayensis Sleumer, Bot. Jahrb. Syst. 78: 465. 1959. TIPO: Paraguay, Paraguari, Salto Pirareta, 23 XI 1950, B. Sparre \& F. Vervoorst 511 (holotipo LIL 381602!; isotipo L cb 0006646!, fragmento ex LIL). Fig. 1

Leucothoë paraguayensis var. calva Sleumer, Bot. Jahrb. Syst. 78: 465. 1959. TIPO: Paraguay, Amambay, Sierra de Amambay, Cerro Corá, VII 1933, T. Rojas 6189 (holotipo, SI-211862!; isotipo L cb 0006647!, fragmento ex SI).

Arbustos o arbolitos hasta $3 \mathrm{~m}$ de altura. Ramas jóvenes con pubescencia variada, densa o esparcida, incluso provistas de pelos glandulosos, típicamente con médula desde hueca a irregularmente septada. Hojas con lámina ovada, de 1,8-5,2 × 0,7-2,2 cm, ápice acuminado, márgenes enteros o apenas ondulados, plana $o$ algo revoluta hacia la base, coriácea, pubescentes sólo sobre nervio medio en la haz y densa a moderadamente pubescente en el envés, tanto en el nervio medio como en la superficie; pecíolos de 2,5-6 mm. Inflorescencias en racimos axilares en la parte superior de las ramas, de (1,5-)4-9 cm de largo, el eje provisto de escasos pelos glandulares o con pubescencia densa a moderada. Flores largamente pediceladas, pedicelos de 3-9 cm; cáliz con ápice acuminado, 5-mero, pubescente en la cara abaxial; corola rojiza, cilíndrica, de 6,5-9 $\mathrm{mm}$ de largo y limbo breve, 5-dentado. Fruto capsular, cápsulas maduras subglobosas, 3,5-4,5 $\times 5-6,5 \mathrm{~mm}$, placenta $+/$ - central. Semillas 0,9-1,8 mm.

Distribución y hábitat. Este de Paraguay y sur de Misiones (departamento San Ignacio). Áreas rocosas, pendientes empinadas, laderas y barrancas en cursos de agua. Florece agosto/ diciembre.

\section{Material representativo examinado}

ARGENTINA. Misiones. Depto. San Ignacio, Teyucuaré, peñón Reina Victoria, Medán et al. 108 (BAA).

Empetrum L., Sp. Pl. 2: 1022. 1753. ESPECIE TIPO: Empetrum nigrum L., lectotipo designado por N. L. Britton \& A. Brown, Ill. Fl. N.U.S. (ed. 2) 2: 479. 1913.

Arbustos achaparrados, postrados, formando carpetas leñosas muy densas. Hojas espiraladas a verticiladas aún en la misma planta, láminas lineares con márgenes recurvados (subrrevolutos) replegados y ocultando parte de la superficie abaxial y sus estomas. Flores solitarias, axilares, diclinas; perianto formado por 6 piezas en 2 series, subtendidas por 2 profilos y 2-4 bractéolas; estambres 3; gineceo súpero, ovario 6-9-locular, estilo grueso y estigma lobulado. Fruto rojo, ocasionalmente negruzco, globoso, conteniendo 7-9 pirenos, rodeado en la base por el perianto, estilo y estigma persistentes.

Género con dos especies en el mundo, una de ellas nativa del hemisferio norte, en regiones templadas de Eurasia, Corea, Japón, Groenlandia y en los Estados Unidos de América, la otra nativa de Sudamérica austral, presente en la Argentina. 


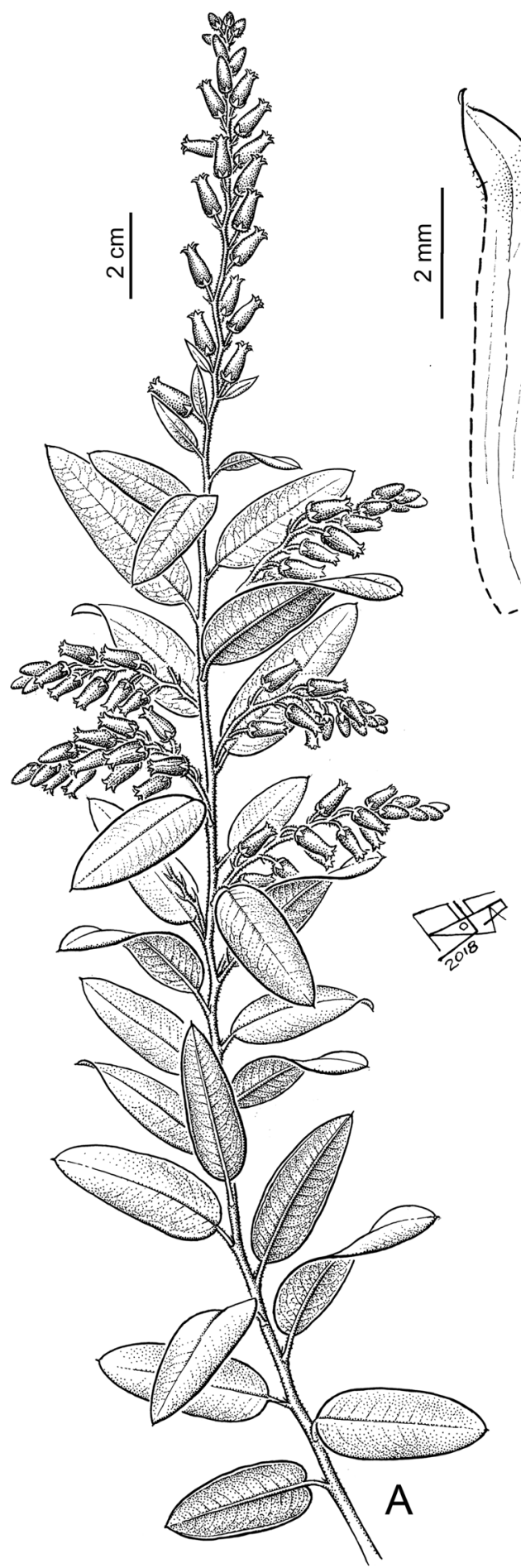

Fig. 1. Agarista paraguayensis. A, rama florífera. B, flor, vista lateral. C, flor, corola desplegada mostrando el androceo, porción superior del estilo y estigma. D, gineceo. E, fruto. A-D, de Keller \& Franco 5878 (SI); E, de Biganzoli \& Giraldo-Cañas 456 (SI). Ilustrador: Francisco Rojas. 
Empetrumrubrum VahlexWilld.,Sp.Pl.(ed.4)4(2): 713.1806. Empetrum nigrum var. rubrum (Vahl ex Willd.) A. DC., Prodr. 16(1): 26. 1869. SINTIPOS: Chile, "Habitat ad Fretum Magellanicum". P. Commerson s.n. (C cb 10010875!, C cb 10010873!).

Arbustos ericoides, dioicos, raro polígamos (y entonces existen pies con flores perfectas), rizomatosos, radicantes, formando matas ramosas; ramas largas, postradas, las viejas casi desprovistas de hojas, grisáceas a castañas, las jóvenes lanuginosas. Hojas ericoides, lineares, de 2-6 6 0,8 $\mathrm{mm}$, densas hacia el ápice de las ramas, pubescentes en los bordes. Flores solitarias, sésiles o subsésiles, axilares, profilos y bractéolas hialinos, enervios, con pelos largos y ondulados en el ápice, las estaminadas con o sin pistilodio, las pistiladas con androceo nulo o reducido; sépalos de 1-2 × 1-1,5, hialinos en el margen; pétalos rosados a rojizos, elípticos o espatulados. Fruto drupáceo (nuculanio), rojo a granate, de 4-7 mm diám., con 7-9 pirenos rugosos, de 1-2 $\mathrm{mm}$, castaños a rojizos, con el dorso convexo y las caras laterales planas. Semillas elipsoides.

Iconografía. Sleumer, H. \& P. M. Hermann. 1999. 8(6): 20, fig. 11.

Nombres vulgares. "Brecillo", mirtilla", "mirtilla de Magallanes", "uvilla de la perdiz".

Distribución y hábitat. Patagonia argentina y chilena, islas Malvinas y en el Atlántico sur, en la isla Tristan Da Cunha. Plantas heliófilas a elevadas altitudes (2600-2750 m s.m.); colonizan suelos desnudos y degradados.

\section{Material representativo examinado}

ARGEnTINA. Chubut. Depto. Cushamen, Lago Puelo, picada entre puesto de Gendarmería y límite con Chile, Rossow et al. 2189 (BAB). Neuquén. Depto. Minas, extremo norte de la Laguna Varvarco, cajón Benítez, puesto Puerta Vieja, Boelcke et al. 14314 (BAA, BAB, SI!).

Río Negro. Depto. Bariloche, Parque Nacional Nahuel Huapi, Cerro Tronador, entre Mallín Chileno y Refugio, Boelcke \& Correa 5723
(BAB). Santa Cruz. Depto. Güer Aike, Ruta Nacional 40, a $10 \mathrm{~km}$ de Cancha Carreras (4220 m s.m.) hacia estancia Tapi Aike y Esperanza, Leuenberger \& Arroyo 3655 (B, BAA). Tierra del Fuego, Antártica e Islas del Atlántico Sur. Depto. Ushuaia, Isla de los Estados, Puerto Cook, ladera E, Nicora et al. 7274 (BAA, BAB).

Gaultheria L., Sp. Pl. 1: 395. 1753. ESPECIE TIPO: Gaultheria procumbens L.

Arbustos erectos, a veces procumbentes. Hojas alternas, simples, coriáceas, con el margen aserrado, dentado o denticulado. Flores perfectas (monoclinas) e imperfectas (diclinas), en racimos, panículas o rara vez solitarias; cáliz 5-partido, segmentos más o menos profundos; corola urceolada o campanulada con 5 lóbulos extendidos o reflejos; androceo con 10 estambres inclusos, filamentos insertos en la base del tubo, más o menos dilatados en la base; anteras provistas de 2 aristas verticales (algunas veces múticas); gineceo con ovario súpero, con 5 lóculos pluriovulados, estilo simple, estigma entero. Fruto una cápsula rodeada por el cáliz carnoso o una baya con el cáliz persistente. Semillas pequeñas, subglobosas o un poco angulares.

Género con alrededor de 130 especies de América, Asia (desde los Himalayas al Japón) y Oceanía (Malasia, Filipinas, Nueva Guinea). En la Argentina habitan 12 especies y dos variedades.

Observaciones. Ha sido complejo, en el tiempo, dilucidar si efectivamente Gaultheria y Pernettya Gaudich. constituyen un mismo género, tal como lo plantean Middleton \& Wilcock (1990). Respecto de las especies de la Argentina y Chile es importante señalar que no existen dudas respecto a la existencia de dos grupos "morfológicos" distintos, sin transiciones, "Gaultheria" con fruto tipo cápsula, rodeado por los sépalos acrescentes en la madurez y "Pernettya", cuyo fruto es una baya verdadera, no habiéndose observado en el numeroso material examinado ni en la experiencia de los autores, ejemplares con caracteres intermedios. En el últi- 
mo tiempo se mantiene, sin embargo, la tendencia de incluir a las especies en un mismo género (cfr. Stevens \& al.: 182, 2004). Bush et al. (2009), con base en estudios moleculares, proponen que las especies que forman bayas verdaderas tales como Gaultheria insana (Molina) D. J. Middleton, $G$. mucronata (L. f.) Hook. \& Arn., G. poeppigii DC., y G. pumila (L. f.) D. J. Middleton forman un grupo de afinidad, lo mismo que aquéllas con cápsulas y sépalos acrescentes como G. phillyreaefolia (Pers.) Sleumer, G. tenuifolia (Phil.) Sleumer y G. nubigena (Phil.) Burtt \& Sleumer, en tanto que G. antarctica Hook. f., y G. caespitosa Poepp. \&
Endl., también con cápsulas y sépalos acrescentes, formarían parte de otro clado.

En cuanto al sistema reproductivo, si bien algunas especies son monoclinas, ya que cuentan con flores perfectas (hermafroditas), la mayoría son dioicas. Entre éstas, figuran cinco especies patagónicas [Gaultheria antarctica, $G$. caespitosa, G. phillyreaefolia, G. tenuifolia y Pernettya insana (Molina) Gunckel = G. insana , las que Cambi \& Hermann (1989) identifican como funcionalmente dioicas, aunque dada la presencia de flores perfectas mejor les cabe considerarlas ginodioicas.

\section{Clave de las especies de Gaultheria en Argentina}

1. Fruto una cápsula envuelta en la madurez por el cáliz carnoso y acrescente .................................................. 2

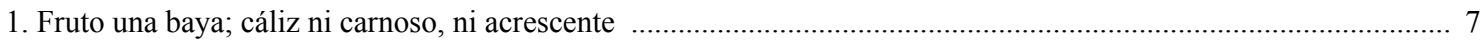

2(1). Hojas con cilios muy evidentes en el borde ............................................................................ G. nubigena

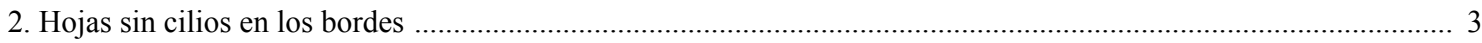

3(2). Flores de color rojo intenso. Hojas cortamente acuminadas, sin mucrón .............................................. G. erecta

3. Flores de color blanco, más raramente rosadas. Hojas mucronadas ............................................................... 4

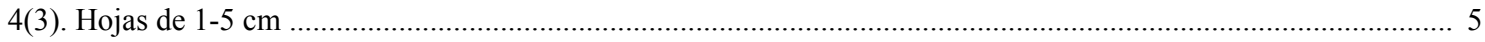

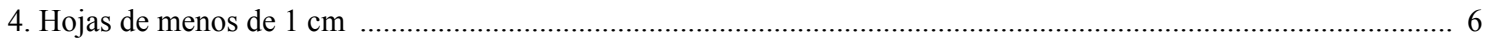

5(4). Hojas de 1-2 cm, ovadas hasta oblongas, raras veces lanceoladas u ovadas .............................. G. phillyreifolia

5. Hojas mayores que $2 \mathrm{~cm}$, linear-elípticas hasta elíptico-oblongas ....................................................... G. tenuifolia

6(4). Hojas elíptico-oblongas, con el margen entero o con 1-3 dientes muy cortos. Flores tetrámeras. Cáliz blanco en la madurez del fruto ............................................................................................................................... G. caespitosa 6. Hojas ovado-oblongas, margen con 4-6 (8) dientes marcados. Flores pentámeras. Cáliz rojo a la madurez del fruto ................................................................................................ G. antarctica 7(1). Flores dispuestas en cimas racemiformes densas, multifloras. Hojas más frecuentemente de 5-9 cm. Corola de $6-7 \mathrm{~mm}$ G. insana

7. Flores solitarias o en cimas 1-2 floras. Hojas generalmente menores que $5 \mathrm{~cm}$. Corola de 2,5-4 mm 8 $8(7)$. Arbustos de hasta $10 \mathrm{~cm}$ de altura, con ramas tendidas o erguidas. Hojas de 2-3 (6) mm, margen entero. Pedúnculo del fruto de hasta $5 \mathrm{~mm}$

G. pumila

8. Arbustos siempre erguidos, mayores que $10 \mathrm{~cm}$ de altura. Hojas con el margen aserrado o crenado, raro entero, con más de 2 dientes a cada lado, a veces, con un mucrón apical poco pronunciado. Fruto con pedúnculo menor de $2 \mathrm{~mm}$

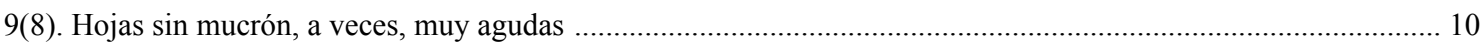

9. Hojas con un mucrón apical generalmente fuerte (aunque en G. marticorenae, poco desarrollado) ...................... 11

10(9). Flores morfológicamente y funcionalmente perfectas. Hojas con la nervadura secundaria visible. Sépalos en el fruto maduro de color violáceo oscuro. Fruto más frecuentemente morado. Pastizales serranos de Jujuy y Salta G. myrsinoides

10. Plantas diclinas, flores estaminadas con pistilodio; las pistiladas, con estaminodios. Hojas con la nervadura secundaria inaparente. Sépalos en el fruto maduro de color verde. Fruto más frecuentemente blanco, rosado o morado. Centro (Córdoba) y bosques andino-patagónicos G. poeppigii

11(9). Hojas lanceolado-elípticas a lineares, de 1-3 mm de ancho G. marticorenae 11. Hojas ovado-elípticas hasta ovado-oblongas, de 4-10 $\mathrm{mm}$ ancho G. mucronata 
Gaultheria antarctica Hook.f., Fl. Antarct. 2: 327 , tab. 116. 1846. Arbutus serpyllifolia Lam., Encycl. 1: 228. 1783. Pernettya serpyllifolia (Lam.) DC., Prodr. 7(2): 587. 1839. Brossaea antarctica (Hook. f.) Kuntze, Revis. Gen. Pl. 2: 387. 1891. Gaultheria serpyllifolia (Lam.) Skottsb., Kongl. Svenska Vetenskapsakad. Handl. 56(5): 282. 1916, hom. illeg., non Pursh, 1813. TIPO: Chile. Détroit de Magellan, P. Commerson 7 (holotipo P-LAM; isotipos MPU 012409!, P cb 00549152!, P cb 00549153!) (cfr. B. L. Burtt, Kew Bull. 1934: 401-402).

Subarbustos enanos, dioicos, de hasta $10 \mathrm{~cm}$ de altura. Ramas delgadas y procumbentes. Hojas laxas, con pecíolo de $0,5 \mathrm{~mm}$; láminas glabras, coriáceas y lustrosas, ovado-oblongas, de (3) 4-7 x 1,5-3 (5) $\mathrm{mm}$, algo agudas, margen engrosado, con 4-6 (8) dientes pequeños y redondeados a cada lado; venación apenas visible. Flores solitarias, axilares, pedicelo de alrededor de $0,5 \mathrm{~mm}$ en las flores pistiladas y de $1-1,5 \mathrm{~mm}$ en las estaminadas, rodeadas en la base por 6 pequeñas brácteas, las dos superiores opuestas e insertas inmediatamente debajo del cáliz, éste 5-lobulado, lóbulos de alrededor de 1,3 $\mathrm{mm}$, triangulares y obtusos. Flores estaminadas con corola de $3 \mathrm{~mm}$, campanulado-esférica; estambres 10 , todos del mismo tamaño, con anteras papilosas, de $0,5 \mathrm{~mm}$ de largo. Flores pistiladas con corola de $2 \mathrm{~mm}$. Fruto, una cápsula de $4,5 \mathrm{~mm}$ de diámetro, globosa hasta turbinada, rodeada por los sépalos de color rojo, engrosados y carnosos, que dejan visible el ápice de la cápsula.

Iconografía. Sleumer, H. \& P. M. Hermann. 1999. 8(6): 5, fig. 1.

Distribución y hábitat. Especie nativa de Chile y la Argentina, donde crece en el sur del país, entre las provincias de Neuquén y de Tierra del Fuego. Habita con frecuencia en las turberas o crece como epífita. Florece entre enero y febrero.

Observación. En ausencia de frutos se confunde con Gaultheria pumila var. pumila e incluso con Myrteola nummularia O. Berg (Myrtaceae), con la que comparte el tipo de ambiente.
Material representativo examinado

ARGENTINA. Chubut. Depto. Cushamen, Lago Esperanza, Pérez Moreau s.n. (BA-46203). Río Negro. Depto. Bariloche, entre Puerto Blest y Laguna Frías, Villamil 2839 (SI-110633). Tierra del Fuego, Antártida e Islas de Atlántico Sur. Depto. Ushuaia, Isla de los Estados, Puerto Vancouver, cascada above Bahía Vancouver, below Tres Puntas, Dudley 1062 (SI-110634).

Gaultheria caespitosa Poepp. \& Endl., Nov. Gen. Sp. Pl. 1: 25. 1835. TIPO: Chile. "Crescit in Chile australis summis Andium jugis ad Antuco et Chillán”, XII-1828, E. F. Poeppig s.n. (holotipo W cb 0047607!; isotipo K cb 000442457!). Fig. 4A.

Pernettya minima Phil., Linnaea 29: 11. 1858. TIPO: Chile. Achibueno, Andes de Linares 1856, P. Germain s.n. (lectotipo SGO 53716!, designado aquí; isolectotipos K cb 000442455!, SGO 41830!).

Subarbustos dioicos de 3-5 $\mathrm{cm}$ de altura. Tallos rastreros, radicantes, ramas glabras o apenas pubescentes. Hojas densas, lámina coriácea, algo lustrosa y glabra, elíptico-oblonga, de 2-3 (5) × 1,5-2 $\mathrm{mm}$, obtusa, atenuada en un pecíolo muy corto, entera o con 1-3 dientes redondeados, débiles, a cada lado de las venas, apenas visibles. Flores solitarias, axilares, pedunculadas, glabras, con 2 bractéolas opuestas en la base del pedicelo; cáliz tetrámero, lóbulos de cerca de $1,5 \mathrm{~mm}$, ovado-triangulares; flores estaminadas con corola de 4-5 mm, urceolado-cilíndrica, con 4 (rara vez 5) lóbulos de cerca de $1 \mathrm{~mm}$, estambres 8 (rara vez 10); ovario de $1 \mathrm{~mm}$, estéril; flores pistiladas, de 3-4 $\mathrm{mm}$, ampliamente urceoladas, con 4 (rara vez 5) lóbulos; estambres estériles y gineceo con ovario fértil. Fruto, una cápsula envuelta por los sépalos que se tornan carnosos y adquieren color blanco cuando maduran.

Iconografía. Sleumer, H. \& P. M. Hermann. 8(6): 5, fig. 2.

Distribución y hábitat. Especie nativa de Chile y de la Argentina donde crece desde la provincia de Mendoza hasta la de Tierra del Fuego. En el área norte de la distribución geográfica crece sólo en las vegas altoandinas. 
En cuanto a la biología reproductiva propia de esta especie, del protólogo y de la ilustración que le acompaña (Tab. 40), se desprende que las flores son perfectas. Por su parte, Cambi \& Hermannn (1989) la consideraron funcionalmente dioica, reconociendo más tarde (Hermann \& Cambi, 1992) que en realidad es ginodioica.

\section{Material representativo examinado}

ARGENTINA. Chubut. Depto. Futaleleufú, Parque Nacional Los Alerces, cordón Situación, Pérez-Moreau s.n. (BA 49609). Neuquén. Depto. Los Lagos, Parque Nacional Nahuel Huapi, lago Espejo Chico, alrededores de la cumbre del cerro La Mona, Escurra 3333 (SI). Río Negro. Depto. Bariloche, cerro Catedral, $200 \mathrm{~m}$ final del tercer tramo de la aerosilla Robles, Villamil 2999 (SI). Tierra del Fuego, Antártida e Islas de Atlántico Sur. Depto. Río Grande, $15 \mathrm{~km}$ al NE de la hostería Kaiken (ACA) por RN 3, Fortunato 4862 (BAB).

Gaultheria erecta Vent., Descr. Pl. Nouv.: tab. 5. 1800. Brossea erecta (Vent.) Kuntze, Rev. Gen. Pl. 2:388. 1891. TIPO. Perú, ex horto Celsiano, 1792 (lectotipo G cb 00352077! designado por J. Luteyn, Fl. Neotrop. Monogr. 66: 475. 1995; isolectotipos C cb 10010944!, F cb 0040427F!, fragmento ex B, L cb 0007087!, fragmento ex G, MO-337191!). Fig. 4F.

Gaultheria saltensis Sleumer, Darwiniana 11(2): 273. 1957. TIPO: Argentina. Salta, Santa Victoria, Toldos, cuesta San José, 2750 m s.m., 7 II 1953, H. O. Sleumer 3833 (holotipo LIL!; isotipos L cb 0007086!, S cb 05-4317!, SI cb 001351!, US cb 00323590!, US cb 00997459!,).

Arbustos de 30-150 cm de altura. Tallos jóvenes densamente ferruginoso-lanosos, os más viejos, glabrescentes. Hojas con pecíolos de 4-7 mm, lámina coriácea, glabra, lustrosa en la haz y con pelos ferruginosos en el envés, de contorno elíptico a ovado, de 5-11 $\times 2,5-6,5 \mathrm{~cm}$, ápice cortamente acuminado, margen entero con unos 5 pares de nervaduras secundarias. Flores perfectas, dispuestas en racimos axilares o terminales de 3-6 cm; pedicelo de $6-10 \mathrm{~mm}$, con 2 bractéolas en la base; cáliz partido hasta la mitad, 5-lobulado; corola urceolado- cilíndrica, de color rojo intenso, de 6-7, con 5 lóbulos breves en el ápice. Androceo con 10 estambres de longitud similar; ovario globoso, subseríceo. Fruto, una cápsula pequeña rodeada por el cáliz acrescente que a la madurez del fruto es azul oscuro.

Iconografía. Cabrera, A. L. 1983. 13(8): 7, fig. 3 (sub Gaultheria saltensis).

Distribución y hábitat. Ampliamente distribuida en América Central y Sudamérica. En la Argentina, crece en las provincias de Salta y Jujuy. Por sus atractivas características ha sido informalmente recomendada como especie ornamental (Cabrera, 1983).

\section{Material representativo examinado}

ARGENTINA. Jujuy. Depto. Ledesma, Ruta Provincial 83, Abra de Cañas, $29 \mathrm{~km}$ del desvío de la Ruta Nacional 34 camino a Valle Grande, Parque Nacional Calilegua, Morrone 3510 (SI). Salta. Depto. Santa Victoria, $4 \mathrm{Km}$ de Los Toldos, camino a Lipeo, Morrone 3865 (SI).

Gaultheria insana (Molina) D.J. Middleton, Edinburgh J. Bot. 47(3): 297. 1990. Hippomanica insana Molina, Sag. Stor. Nat. Chili: 126, 351. 1782. Pernettya insana (Molina) Gunckel, Not. Mens. Mus. Nac. Hist. Nat. 17(197): 6. 1972. TIPO: Chile (no designado). Fig. 4B.

Arbutus furiens Hook. \& Arn., Bot. Beechey Voy.: 33. 1830. Gaultheria furiens (Hook. \& Arn.) Hook. \& Arn., J. Bot. (Hooker) 1: 281. 1834. Pernettya furiens (Hook. \& Arn.) Klotzsch, Linnaea 24: 83. 1851. TIPO: Chile. "Hab. Conception" (probablemente en K).

Arbutus punctata Hook. \& Arn., Bot. Beechey Voy.: 33. 1830. Gaultheria punctata (Hook. \& Arn.) Hook. \& Arn, J. Bot. (Hooker) 1: 281. 1834, hom. illeg., non Blume, 1826. Pernettya punctata (Hook. \& Arn.) Klotzsch, Linnaea 24: 83. 1851. TIPO: Chile. Conceptionis, F. W. Beechey s.n. (K cb 000641626!).

Arbutus vernalis Poepp. \& Endl., Nov. Gen. Sp. Pl. 1: 26, tab. 42. 1836. Gaultheria vernalis (Poepp. \& Endl.) Kunze, Prodr. 7(2): 594. 1839. Pernettya vernalis (Poepp. \& Endl.) Phil., Anales Univ. Chile 18(1): 65. 1861. Brossaea vernalis (Poepp. \& 
Endl.) Kuntze, Revis. Gen. Pl. 2: 388. 1891. TIPO: Chile australis, in rupestribus ad Talcahuano, IX 1828, E. F. Poeppig s.n., Coll. pl. Chil. III. 119, Syn. pl. Amer. austr. msc. Diar 621 (holotipo W cb 0047604!; isotipos F cb 0055233F!, G cb 00323483!, HAL cb 0060237!, MO-345687!, NY cb 00008224!, NY cb 00008225!, P cb 00715695!). Pernettya melanocarpa Phil., Anales Univ. Chile 65: 59. 1884. TIPO: "Chile. In montibus de Villagran dictis praedii Colcura sub grado 37 latitud, inveni", III 1884, R. A. Philippi s.n. (lectotipo SGO 53713! designado aquí; isolectotipo SGO 41786!).

Arbustos dioicos de 1-5 m de altura. Tallos delgados y erguidos, los jóvenes finamente pubescentes, laxamente cubiertos con setas más o menos adpresas, de color negruzco-rojizo. Hojas pecioladas, lámina elíptica hasta oblongo-elíptica, de 25-50 (85) x 15-25 (40) $\mathrm{mm}$, más o menos anchamente cuneada y atenuada gradualmente hacia el ápice, terminando en una punta glandular algo obtusa, subcoriáceas, cubiertas en ambas caras por setas de cerca de $1 \mathrm{~mm}$, laxas o más o menos adpresas, de color castaño, que dejan puntos castaño-rojizos al desprenderse, envés pubescente; margen frecuentemente revoluto con dientes pequeños y redondeados. Flores dispuestas en cimas racemiformes, densas, de 20-30 (50) mm, con 6-20 flores blancas. Pedúnculos y pedicelos a veces densamente pubescentes y siempre cubiertos por pelos rígidos, rojizos, ramificados desde su base, provistos de una bráctea pequeña en su base y de 2 bractéolas subopuestas en su cuarto o tercio inferior; cáliz profundamente 5-partido, lóbulos de 2,5 mm, alargado-triangulares, ciliados y pubescentes; flores estaminadas con corola de 7 $\mathrm{mm}$, oblongo-urceolada y pilosa en su cara interna; estambres 10, 5 de ellos más cortos; anteras de 1,2-2 mm, fértiles; gineceo con pistilodio estéril; flores pistiladas con corola de $6 \mathrm{~mm}$, urceolada y pilosa en su cara interna; estambres con las anteras estériles; gineceo con ovario glabro, fértil, estilo de 3-4,5 mm con el estigma bien desarrollado. Fruto, una baya globosa, de 5-6 mm diámetro, de color blanco-rojizo, a veces, purpúreo-negruzco.

Iconografía. Sleumer, H. \& P. M. Hermann. 1999. 8(6): 9, fig. 5 (sub Pernettya insana).
Nombre vulgar. "Hued-hued".

Distribución y hábitat. Planta nativa de Chile y Argentina, donde crece en la provincia de Chubut en los bosques andino-patagónicos.

Observación. No existen "tipos" físicos de las plantas descritas por Molina, pero se aceptan aquellas descripciones que sean claramente reconocibles (Gunckel, 1972).

\section{Material representativo examinado}

ARGENTINA. Chubut. Depto. Cushamen, lago Puelo, embarcadero Los Hitos (ejemplar pistilado), C. Villamil 3504 (BBB). Idem (ejemplar estaminado), Villamil 3505 (BBB).

Gaultheria marticorenae Teillier \& P.W. Fritsch, Gayana, Bot. 73(1): 66. 2016. Pernettya angustifolia Lindl., Edwards's Bot. Reg. 26: tab. 63. 1840. Pernettya mucronata var. angustifolia (Lindl.) Reiche, Anales Univ. Chile 117: 491. 1906. Gaultheria mucronata var. angustifolia (Lindl.) D.J. Middleton, Edinburgh J. Bot. 47(3): 298. 1990. Gaultheria angustifolia (Lindl.) Teillier, Gayana, Bot. 70(1): 138. 2013, hom. illeg., non Brandegee, 1908. TIPO: Cultivado en Birmingham Botanical Garden; procedente de Valdivia, Chile (holotipo, K cb 000641630!; posible isotipo BR cb 000006997090!). Fig. 2.

Gaultheria myrtilloides var. minor Hook. \& Arn., J. Bot. (Hooker) 1: 281. 1834. TIPO: Chile. "Moist places near Valdivia and in the island of Chiloé”, T. C. Bridges 565 (E cb 00326849!, K cb 000641631!, K cb 000641632!).

Pernettya leucocarpa var. linearis Reiche, Anales Univ. Chile 117: 494. 1906. TIPO. Chile. Nadi de Puyehue, I 1905, K. Reiche s.n. (lectotipo SGO 3783!, designado por S. Teillier et al., Gayana, Bot. 73: 66. 2016).

Arbustos dioicos de 20-100 $\mathrm{cm}$ de altura. Tallos erguidos, a veces radicantes. Hojas glabras, discolores, con las venas principales fuertemente marcadas en el envés; pecíolo corto; lámina linear a lanceolado-elíptica u oblonga, de 12-15 (18) × $3 \mathrm{~mm}$, atenuada en el ápice y en la base, de consistencia poco 
rígida y mucrón breve; margen aserrado, con dientes muy agudos hasta mucronulados. Flores solitarias, axilares, pedicelo de 4-8 $\mathrm{mm}$; cáliz 5-partido, lóbulos de $2 \mathrm{~mm}$, angostamente triangulares, algo agudos; flores estaminadas con corola de alrededor de $5 \mathrm{~mm}$, campanulada; androceo con 10 estambres, filamentos de 1,2 a $1,5 \mathrm{~mm}$; ovario de $1,2 \mathrm{~mm}$, piriforme, estéril; flores pistiladas con corola de alrededor de $4 \mathrm{~mm}$, urceolado-cilíndrica; estambres estériles; gineceo con ovario fértil, estigma con 5 lóbulos bien desarrollados. Fruto, una baya casi globosa, de 6-8(10) mm de diámetro, deprimida en la base y en el ápice, de color rosado a rojiza, cáliz ni acrescente ni carnoso.

\section{Nombre vulgar. "Chaura".}

Distribución y hábitat. Especie nativa de Chile y Argentina, donde crece en las provincias de Neuquén y de Río Negro. Se ubica en sitios húmedos, soporta incluso los suelos anegados.

\section{Material representativo examinado}

ARGENTINA. Neuquén. Depto. Los Lagos, Quetrihué, costa lago Nahuel Huapi, en punta Gaviota, Diem 1782 (SI). Río Negro. Depto. Bariloche, Ruta 258, río Villegas, Sánchez 740 (BAB).

Gaultheria mucronata (L. f.) Hook. \& Arn., J. Bot. (Hooker) 1: 281. 1834. Arbutus mucronata L. f., Suppl. Pl.: 239. 1782. Pernettya mucronata (L. f.) Gaudich. ex A. Spreng., Syst. Veg. 4(2): 158. 1827. TIPO: Chile. "Habitat in Tierra del Fuego", J. G. A. Foster s.n. (holotipo, cb LINNHS792-19!). Fig. 4C-D.

Arbutus rigida Banks \& Sol. ex Hook. f., Fl. Antarct. 2: 326. 1846, nom. nud. Pernettya oblongifolia Hombr. \& Jacq. ex Decne., Voy. Pôle Sud 2: 28, tab. 22 bis, fig. M. 1852, nom. nud. pro syn.

Pernettya ovalifolia Hombr. \& Jacq. ex Decne., Voy. Pôle Sud 2: tab. 22bis, fig. L. 1852, nom. nud. pro syn.

Pernettya mucronata var. microphylla Hombr. \& Jacq. ex Decne., Voy. Pôle Sud. 2: 29, tab. 22, fig. X. 1852. Gaultheria mucronata var. microphylla (Hombr. \& Jacq. ex Decne.) D.J. Middleton,
Edinburgh J. Bot. 47(3): 298. 1990. TIPO: Chile. Magallanes, in rupibus maritimis ad fretum magellanicum, sin colector s.n. (holotipo P).

Pernettya rupicola Phil., Linnaea 29: 10. 1858. Pernettya mucronata var. rupicola (Phil.) Reiche, Anales Univ. Chile 117: 490. 1906. TIPO. Chile. Valdivia, in rupibus prope Corral, R. A. Philippi s.n. (holotipo SGO 53710!).

Pernettya litoralis Phil., Anales Univ. Chile 27(2): 319. 1865. TIPO: Chile. Hueicoya, F. Philippi s.n. (lectotipo SGO 41829!, designado aquí, isolectotipo SGO 53711!).

Pernettya parvifolia Phil., Anales Univ. Chile 90: 194. 1895, hom. illeg., non Benth., 1845.

Pernettya mucronata var. microphylla Phil. ex Reiche, Anales Univ. Chile 117: 491. 1906, hom. illeg., non Decne., 1852. Pernettya mucronata var. parvifolia (Phil.) Skottsb., Kongl. Svenska Vetensk. Handl. n.s. 56: 283. 1916. TIPO: Chile. Magallanes, $R$. $A$. Philippi s.n. (holotipo SGO 53714!).

Pernettya philippii Gand., Bull. Soc. Bot. France. 60: 24. 1913. TIPO: Chile. "Patagonia occ. ins. Wellington ad Heinrichfyord", K. Skottsberg 166 (probablemente en GB, LY).

Arbustos dioicos de 0,2-0,8 (hasta 2,5) $\mathrm{m}$ de altura. Tallos erguidos, robustos, las ramillas, glabras o pubescentes y laxamente setosas. Hojas pecioladas; lámina dura y coriácea, glabra, ovadoelíptica hasta ovado-oblonga, de 1-2 × 0,4-0,6 (1) $\mathrm{cm}$, engrosada en el borde y provista de 4-5 dientes redondeados, gruesos, a cada lado; ápice atenuado y terminado en un mucrón rígido de cerca de $1 \mathrm{~mm}$. Flores unisexuales, solitarias, axilares, rodeadas, en la base, por varias brácteas pequeñas y dos bractéolas casi opuestas; pedicelo de 5-10 (12) $\mathrm{mm}$, finamente pubescente y laxamente setoso; cáliz profundamente 5-partido, lóbulos de $2 \mathrm{~mm}$, angostamente triangulares, algo agudos; flores estaminadas con una corola de alrededor de $5 \mathrm{~mm}$, campanulada; androceo con 10 estambres, anteras de $1 \mathrm{~mm}$, filamentos de 1,2-1,5 mm; gineceo con ovario de $1,2 \mathrm{~mm}$, piriforme, estéril; flores pistiladas con una corola de cerca de $4 \mathrm{~mm}$, urceolado-cilíndrica; estambres estériles; gineceo con ovario fértil, estigma con 5 lóbulos bien desarrollados. Fruto, una baya casi globosa, de 6-8 (10) $\mathrm{mm}$ de diámetro, algo deprimida, de color rosa a rojizo, raro blanco, cáliz ni acrescente ni carnoso. 


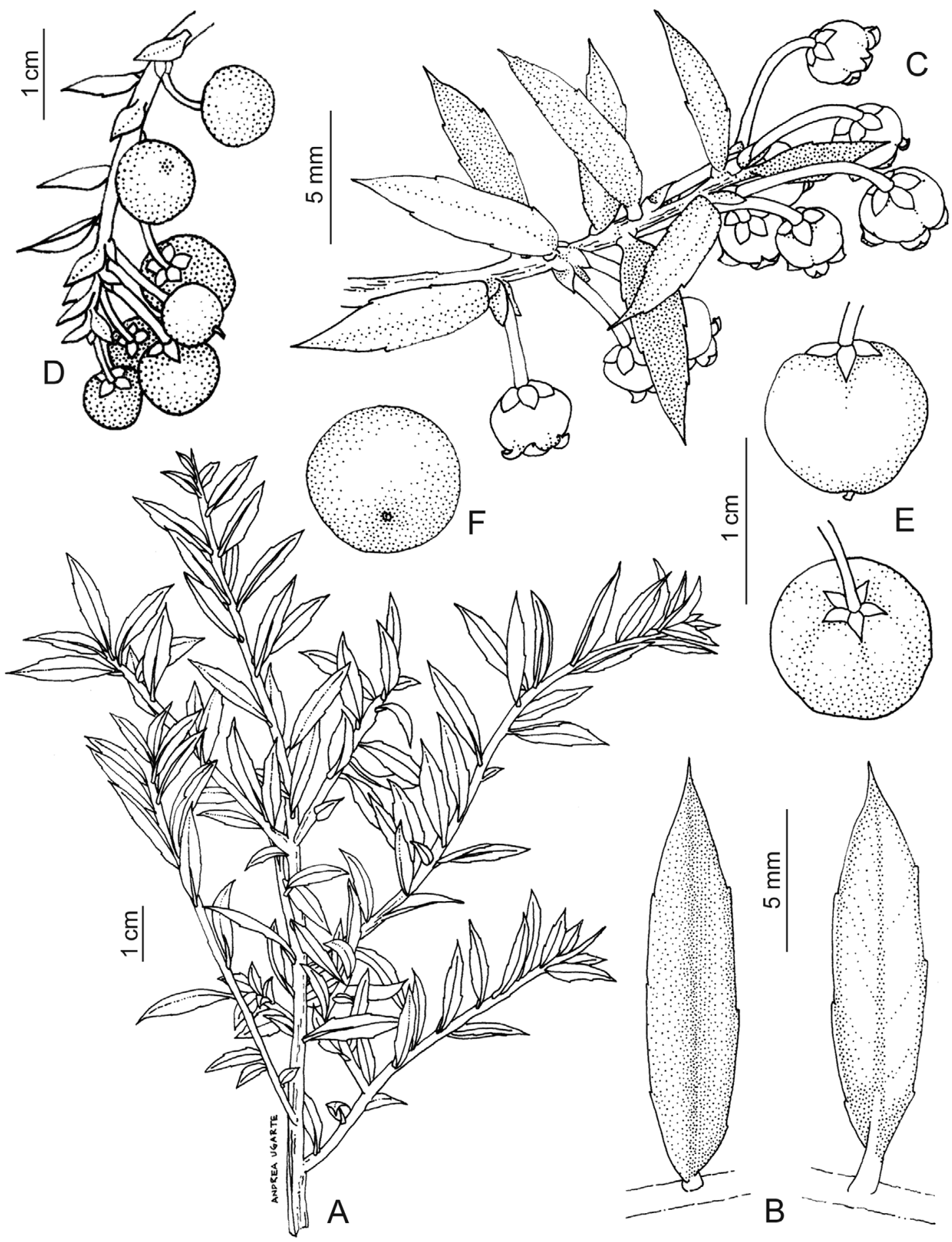

Fig. 2. Gaultheria marticorenae. A, porción de una rama. B, hoja (caras adaxial y abaxial). C, porción de una rama florífera. D, porción de una rama fructífera. E, F, fruto. A-F de Montaldo 4 (SGO). Ilustrador: Andrea Ugarte. 
Iconografía. Sleumer, H. \& P. M. Hermann. 1999. 8(6): 14, fig. 8 (sub Pernettya mucronata).

Nombre vulgar. "Chaura".

Distribución y hábitat. Especie nativa de Chile y de la Argentina, donde crece entre las provincias de Neuquén y de Tierra del Fuego. Se encuentra principalmente en los bosques de Nothofagus siempreverdes.

Observación. Teillier \& Escobar (2013) incluyeron erróneamente a Pernettya philippii Gand. en la sinonimia de G. phyllireifolia (Pers.) Sleumer.

\section{Material representativo examinado}

ARGENTINA. Chubut. Depto. Cushamen, lago Puelo, picada al puesto de Gendarmería, Rossow 2166 (BAB). Santa Cruz. Depto. Lago Argentino, Parque Nacional Los Glaciares, camping Arroyo Correntoso, Cocucci 2497 (CORD, CTES). Tierra del Fuego, Antártida e Islas de Atlántico Sur. Depto. Ushuaia: isla de los Estados, Puerto Cook, ladera E, Nicora 7191 (BAB).

Gaultheria myrsinoides Kunth, Nov. Gen. Sp. (quarto ed.) 3: 283. 1819. TIPO: Colombia. "Crescit juxta urbem Almaguer Novo-Granatensium", F. W. H. A. von Humboldt \& A. J. A. Bonpland 2087 (P cb 00670992!).

Andromeda prostrata Cav., Icon. 6: 43, tab. 562, fig.

2. 1801. Pernettya prostrata (Cav.) DC., Prodr. 7: 609. 1839 (non Gaultheria prostrata W. W. Sm., 1920). TIPO: Ecuador. Volcán Tungurahua, L. Nee s.n. (holotipo MA cb 651909!).

Pernettya pentlandii DC., Prodr. 7: 587. 1839. Pernettya purpurea var. pentlandii (DC.) Kuntze, Revis. Gen. Pl. 3(2) 193. 1898. Pernettya prostrata var. pentlandii (DC.) Sleumer, Notizbl. Bot. Gart. Berlin-Dahlem 12: 290, 647. 1935. TIPO: Bolivia. "Ad montes excelsiores”, 1829, J. B. Pentland s.n. (holotipo G-DC cb 00323420!).

Arbustos achaparrados de 10-20 cm de altura. Tallos jóvenes pubescentes, los más viejos, con cicatrices conspicuas. Hojas con pecíolo de
1-2 mm, lámina glabra, coriácea, lanceolada a lanceolado-elíptica, de 8-12 × 4-6 mm, aguda, con el borde aserrado, dientes muy pequeños. Flores perfectas, solitarias, nutantes; cáliz glabro 5-partido; corola campanulado-urceolada, con los pétalos blancos, de $4 \mathrm{~mm}$; androceo con 10 estambres, 5 cortos y 5 largos; gineceo con ovario glabro, globoso. Fruto, una baya violácea, globosa, pero deprimida en los extremos, de 4-6 mm de diám., sépalos no acrescentes.

Iconografía. Cabrera, A. L. 1983. 13(8): 5, fig. 2 (sub Pernettya prostrata var. purpurea).

Distribución y hábitat. Especie nativa con una amplia distribución en América, desde México hasta la Argentina, donde es rara; crece en las provincias de Jujuy y Salta, en pastizales serranos entre 2800 y $4100 \mathrm{~m}$ de altitud.

\section{Material representativo examinado}

ARGENTINA. Jujuy. Depto. Tilcara, camino de abra del Potrero a Molulo, Zuloaga et al. 11676 (SI). Salta. Depto. Santa Victoria, de abra de Lizoite a Santa Victoria, Kiesling et al. 3928 (SI).

Gaultheria nubigena (Phil.) Burtt \& Sleumer, Notizbl. Bot. Gard. Berlin-Dahlem 13: 207. 1936. Pernettya nubigena Phil., Anales Univ. Chile 18: 64. 1861. TIPO: Chile. Ensenada de Reloncaví, R. Pearce s.n. (holotipo SGO 53701!).

Arbustos bajos, compactos. Tallos postrados o procumbentes, delgados y glabros. Hojas glabras en la haz y finamente pubescentes en el envés, lámina ovada hasta redondeadoovada, de $(0,7) 1-1,6(2,5) \times(0,4) 0,8-1,2(1,9) \mathrm{mm}$; base redondeada o débilmente cordiforme, ápice agudo; margen delicadamente aserrado con los dientecillos terminados en un cilio muy evidente. Flores perfectas, dispuestas en cimas axilares y terminales de hasta $2 \mathrm{~cm}$, con 5-15-flores, pedúnculo finamente pubescente; pedicelo de 3-4 $\mathrm{mm}$ en la axila de una bráctea, con 2 bractéolas opuestas en su base; corola de color blanco con las venas rosadas, de $5 \mathrm{~mm}$, urceolado-cilíndrica; androceo con 10 estambres, 
5 largos y 5 cortos, los más cortos alcanzan la mitad de la corola; gineceo con ovario de $1 \mathrm{~mm}$, glabro, estilo de $2,5 \mathrm{~mm}$ y estigma obtuso. Fruto una cápsula coriácea, los lóbulos del cáliz muy poco engrosados, patentes durante la madurez.

Iconografía. Sleumer, H. \& P. M. Hermann. 1999. 8(6): 5, fig. 3.

Distribución y hábitat. Especie nativa de Chile y la Argentina donde crece en las provincias de Neuquén y Río Negro. Especie andina, habita en ambientes sombríos y húmedos, entre rocas. Es una especie escasa; de acuerdo con la información disponible hasta el momento, se trataría de una especie vulnerable.

Observación. Hermann \& Cambi (2006) reportaron esta especie como rara y vulnerable, ya que por más de 52 años no fue coleccionada y las poblaciones recientemente conocidas en ambos países apenas cuentan con 7-10 ejemplares.

\section{Material representativo examinado}

ARGENTINA. Neuquén. Depto. Los Lagos, cordón del cerro Colu Mahuida subida al Torre, 1400 m s.m., Diem 338 (BAB, LIL). Río Negro. Depto. Bariloche, Parque Nacional Nahuel Huapi, río Manso, cascada Los Alerces, Villamil 10407 (BBB).

Gaultheria phillyreifolia (Pers.) Sleumer, Notizbl. Bot. Gard. Berlin-Dahlem 13: 207. 1936. Arbutus phillyreifolia Pers., Syn. Pl. 1: 483. 1805. Pernettya phillyreifolia (Pers.) DC., Prodr. 7: 587. 1839. TIPO: Perú, J. Dombey s.n. (holotipo P-JUSS; isotipos G cb 00323419!; isotipos G cb 00323419!, G cb 00342266!, P cb 00546381!, P cb 00546382!, P cb 00546383!; MA 747492!). Fig. 4E.

Gaultheria myrtilloides Hook. \& Arn., J. Bot. (Hooker) 1: 281. 1834, nom. illeg. hom., non Cham. \& Schltdl., 1824.

Gaultheria mucronata Phil., Linnaea 29: 12. 1858, hom. illeg., non (L. f.) Hook. \& Arn., 1834. TIPO: Chile. Osorno, 1835, C. Gay 1463 (holotipo SGO 53731!).
Gaultheria florida Phil., Anales Univ. Chile 90: 192. 1895. Gaultheria phillyreifolia var. florida (Phil.) Kausel, Revista Univ. (Santiago) 34: 172. 1949. TIPO: Chile, prope urbem Valdivia, W. Lechler 544 (lectotipo SGO 53734! designado aquí; isolectotipo SGO 41799).

Gaultheria lanceolata Phil., Anales Univ. Chile 90: 193. 1895, hom. illeg., non Hook. f., 1847. TIPO: Chile. Cerro Yate, 1871, C. Juliet s.n. (holotipo SGO 53748!).

Gaultheria myrtilloides var. racemosa Phil. ex Reiche, Anales Univ. Chile 117: 498. 1906. TIPO: Chile. Corral, 1861, H. Krause s.n. (holotipo SGO 53742!).

Arbustos dioicos de 0,8-1,8 (2,5) $\mathrm{m}$ altura. Tallos nuevos pubescentes, provistos de setas densas, de color castaño. Hojas cortamente pecioladas, coriáceas, glabras; lámina ovadooblongas, rara vez lanceoladas u ovadas, de (10) 12-19 (28) × 4-6 mm, base cuneada hasta redondeada, ápice acuminado prolongado en un mucrón punzante, sobre todo en las hojas jóvenes; margen aserrado con (4) 6-8 (12) dientes a cada lado, que terminan en una seta glandular caediza, la cara superior con el borde engrosado y la vena media marcadamente prominente. Flores generalmente solitarias, blancas, perfumadas, dispuestas en las axilas de las hojas superiores, disminuyendo en tamaño en dirección al ápice, algunas veces forman cimas axilares con 3-10-flores; pedicelos de 5-16 mm, delgados, nutantes y provistos de 2-6 (9) bractéolas en la mitad inferior o en toda su longitud; flores estaminadas con cáliz de $2 \mathrm{~mm}$, cuyos lóbulos son agudamente triangulares; corola de $4 \mathrm{~mm}$, cónico-urceolada y pilosa en su cara interna; androceo con 10 estambres desiguales; gineceo con ovario residual, estéril; flores pistiladas con corola de $3 \mathrm{~mm}$ y ovario fértil. Fruto, una cápsula coriácea, de color castaño-claro, dehiscente desde el ápice, rodeada casi completamente por los sépalos, que se tornan carnosos y de un color negro-violáceo hacia la madurez.

Iconografía. Sleumer, H. \& P. M. Hermann. 1999. 8(6): 9, fig. 4.

Nombre vulgar. "Chaura". 
Distribución y hábitat. Especie nativa de Chile y Argentina donde crece desde la provincia de Buenos Aires a la de Chubut. Es uno de los arbustos dominantes en los matorrales secundarios que se originan a partir de la tala de los bosques de Nothofagus dombeyi (Mirb.) Oerst. ("coihue").

Observaciones. El isotipo de Gaultheria phillyreifolia que se encuentra en el Jardín Botánico de Madrid referido como MA 747492 aparece como coleccionado en las islas Cook, lo que es erróneo. La localización del tipo en Perú, también es un error ya que fue coleccionado posiblemente en las cercanías del puerto de Talcahuano (Kausel, 1949).

\section{Material representativo examinado}

ARGENTINA. Buenos Aires. Part. Saavedra, cerro Curamalal Grande, en la cumbre del cerro, Villamil 2562 (BBB, NY, SI). Neuquén. Depto. Los Lagos, Villa Puerto Manzano, establecimiento Genciana, Villamil 2362 (BBB, NY). Río Negro. Depto. Bariloche, Puerto Blest, camino entre la turbera y Puerto Blest, Villamil 3468 (BBB).

Gaultheria poeppigii DC., Prodr. 7(2): 593. 1839. Pernettya poeppigii (DC.) Klotzsch, Linnaea 24: 83. 1851. Gaultheria myrtilloides Poepp. \& Endl., Nov. Gen. Sp. Pl. 1: 25. tab. 41. 1836. hom. illeg., non Cham. \& Schltdl., 1826. Pernettya myrtilloides Zucc. ex Steudel, Nomencl. Bot. (ed. 2) 2: 306. 1841. TIPO: Chile. In Chili australis alpinis ad pico de Pilque in Andibus antucensibus, XI 1828, E. F. Poeppig, Diar. 679 (holotipo W cb 0047603!, isotipos G cb 00352111!; HAL 060238!, P cb 00715706!, W-Rchb. cb 1889-0300629!). Fig. 3.

Pernettya buxifolia Phil., Anal. Univ. Chile 43: 508. 1873. TIPO. Chile. Cordillera de Nahuelbuta, G. Volckmann s.n. (holotipo SGO 53712!; isotipo $\mathrm{B}^{\dagger}$ ), hom. illeg., non $\mathrm{M}$. Martens \& Galeotti, 1842.

Pernettya philippiana Speg., Revista Fac. Agron. Univ. Nac. La Plata 3:548. 1897. Pernettya leucocarpa var. buxifolia (Phil.) Reiche, Anales Univ. Chile 117: 493. 1906.
Pernettya patagonica Speg., Revista Fac. Agron. Univ. Nac. La Plata 3: 547. 1897. TIPO: Argentina. Santa Cruz, in dumetis collinis prope Lago Argentino, F. Tonini del Furia s.n. (holotipo LPS-1620 en LP cb 003156!).

Pernettya phillyreifolia var. araucana Kuntze, Revis. Gen. Pl. 3(3): 192. 1898. TIPO: Chile. Malleco, Río Quino, 17 II 1892, O. Kuntze s.n. (holotipo NY cb 00010289!; isotipos, $\mathrm{B}^{\dagger}, \mathrm{L}$ ).

Pernettya poeppigii var. nana Sleumer, Lilloa 25: 549. 1952. Pernettya myrtilloides var. nana (Sleumer) Sleumer, Bot. Jahrb. Syst. 105(4): 472. 1985. Gaultheria poeppigii var. nana (Sleumer) D.J. Middleton, Edinburgh J. Bot. 47(3): 298. 1990. TIPO: Argentina. Neuquén. Refugio Cerro Colorado, ca. 1600 m s.m., H. O. Sleumer 1597 (holotipo LIL).

Pernettya mucronata var. cordobensis Sleumer, Notizbl. Bot. Gart. Berlin-Dahlem 12: 652. 1935. TIPO: Argentina. Sierras de Córdoba, entre Tanti y el Río Yuspe, 12 II 1876, G. Hieronymus 362 (holotipo $\mathrm{B}^{\dagger}$; isotipos CORD cb 00003636!, $\mathrm{K}$ cb 000641629!, LIL cb 001081!).

Arbustos erguidos, dioicos, de 0,3-1 (1,5) $\mathrm{m}$ de alto, o tendido de 0,1-0,2 m, denso. Tallos nuevos finamente pubescentes y laxamente setosos. Hojas brevemente pecioladas, las más jóvenes fina y laxamente pubescentes, especialmente en los bordes; lámina ovado-elíptica a anchamente oblongo-elíptica, de (8) 10-20 × 3-5 (7) mm, algo aguda a causa de la costilla media algo prolongada, margen engrosado, con 4-5 (7) dientes redondeados a cada lado. Flores solitarias, axilares; pedicelos de 4-5 mm, pubescentes, a veces, con glándulas estipitadas aisladas y caedizas, en la base rodeados por 4 brácteas pequeñas y 2 bractéolas; cáliz profundamente 5-partido, lóbulos de 1,5$2 \mathrm{~mm}$, triangulares; corola de cerca de $3 \mathrm{~mm}$, urceolada; flores estaminadas con 10 estambres, 5 más cortos, con anteras de 1-1,2 mm, anchamente ovoide-oblongas y filamentos de 1-1,5 mm; ovario estéril; flores pistiladas el ovario globoso a piriforme, de 1,5 mm. Fruto una baya globosa o algo deprimida, de 4-6 mm de diámetro, de color blanco, rosado o morado.

Nombres vulgares. "Chaura", "shal”, "sheúkk", "gus", "amain-ngush". 
Distribución y hábitat. Nativa de Chile y de la Argentina donde se encuentra en la provincia de Córdoba y luego entre las de Neuquén y Santa Cruz. Crece preferentemente en el ámbito de los bosques de montaña de Nothofagus dombeyi y N. pumilio (Poepp. \& Endl.) Krasser ("lenga"), también en los matorrales de $N$. antarctica (G. Forst.) Oerst. ("ñire") y en el margen inferior del piso andino.

Observaciones. Por la disyunción que genera en la distribución geográfica de esta especie, habría que revisar la propuesta de Sleumer (1985) de incluir a Pernettya mucronata var. cordobensis Sleumer en la sinonimia de G. poeppigii. Por otra parte, es posible que las colecciones de Pernettya palenae Phil. [Anal. Univ. Chile. 90:195. 1895. TIPO. Chile. Río Palena, 1887, Delfín s.n. (SGO 53705!, 53706! y 53707!)], pertenezcan a esta especie, pero en ausencia de frutos no es posible confirmarlo con seguridad.

Cabe señalar que un duplicado del tipo de $P$. buxifolia en $\mathrm{K}$ fue etiquetado como $P$. philippiana Speg. e identificado por Sleumer como P. prostrata var. pentlandii una especie que Luteyn et al. 1995.) sugieren que no crece en el cono sur de Sudamérica.

\section{Material representativo examinado}

ARGENTINA. Chubut. Depto. Cushamen, Parque Nacional Lago Puelo, subida al cordón Currumahuida, Rossow 4178 (BAB). Córdoba. Depto. Punilla, Sierra Chica, cerro Uritorco, falda occidental, A. T. Hunziker 17981 (CORD). Neuquén. Depto. Aluminé, Villa Pehuenia, predio de cabañas Moquehue, alrededores del lago Aluminé, Belgrano 486 (SI). Río Negro. Depto. Bariloche, Colonia Suiza, refugio camino por tambo en picada hacia monte de colihue, Villamil 2993 (SI).

Gaultheria pumila (L. f.) D.J. Middleton, Edimburgh J. Bot. 47(3): 298. 1990. Arbutus pumila L. f., Suppl. Pl.: 239. 1782. Pernettya pumila (L. f.) Hook., Icon. Pl. 1: tab. 9. 1836. Andromeda humilis Banks \& Sol. ex Hook.f., Fl. Antarct. 2: 326. 1846. TIPO: Chile. Habitat in Tierra del Fuego, J. R. Forster \& G. Forster s.n. (BM cb 000528779!; BM cb 000528780! FR cb 0031036!, LINN-HS792-17!).
Arbustos pequeños, dioicos, generalmente rastreros, cespitosos. Tallos jóvenes pubescentes, sin setas. Hojas casi sésiles, laxamente imbricadas; lámina oblongo-elíptica, de 2-3 (5) × 1,5-2,5 mm, obtusa o algo aguda, coriácea, glabra pero finamente ciliada, con una seta generalmente oscura a cada lado de la base; margen entero, venas poco notorias. Flores solitarias, axilares, pediceladas, con 2-4 brácteas pequeñas y 2 bractéolas; cáliz profundamente 5-partido, lóbulos de $2 \mathrm{~mm}$, ovado-triangulares y con el margen ciliado; flores estaminadas nutantes, pedicelo de 6-10 (20) $\mathrm{mm}$; corola de cerca de $3 \mathrm{~mm}$, algo campanulada; androceo con 10 estambres, casi iguales en tamaño; flores pistiladas erguidas, pedicelos de 1-3,5 mm, corola de 2,5 mm, apenas campanulada; estambres estériles. Fruto, una baya de color rosado o blanco, esférica a elipsoide, de 5-10 mm; sépalos verdes, no acrescentes, pedúnculo algunas veces alargado durante la fructificación, de hasta $5 \mathrm{~mm}$.

\section{Clave de las variedades de Gaultheria pumila}

1. Plantas de 4-6 (8) $\mathrm{cm}$ de alto, ramillas erguidas o procumbentes. Pedúnculo del fruto más corto o del largo de las hojas var. leucocarpa 1. Plantas de $2-3 \mathrm{~cm}$ de alto, rastreras, ramillas delgadas, procumbentes. Pedúnculo del fruto cuatro veces más largo que las hojas var. pumila

Var. leucocarpa (DC.) D.J. Middleton, Edimburgh J. Bot. 47(3): 298. 1990. Pernettya leucocarpa DC., Prodr. 7: 586. 1839. Pernettya empetrifolia (Lam.) Gaudich. var. leucocarpa (DC.) Wedd., Chlor. And. 2: 169. 1857. TIPO: Chile. "In Chili australis rupestribus frigidissimis inter muscos in latere australi montis ignivomi Antucencis ad 8500 ped. alt. Februario flor". E. F. Poeppig, Diar. 933 (holotipo G-DC cb 00323413!; isotipos F cb 0055479F!, HAL cb 0060168!, NY cb 00010284!, P cb 00715738!, W cb 0051015!).

Pernettya leucocarpa var. gayana DC., Prodr.7: 586. 1839. Pernettya gayana (DC.) Hombr. \& Jacq. ex Decne., Voy. Pôle Sud 2: 31, tab. 23 F. 1852. TIPO: Chile. Haute cordiliére, 1833, $C$. Gay s.n. (holotipo G-DC cb 00323414 !, isotipos BR cb 0000006997144!, MPU cb 012417!). 

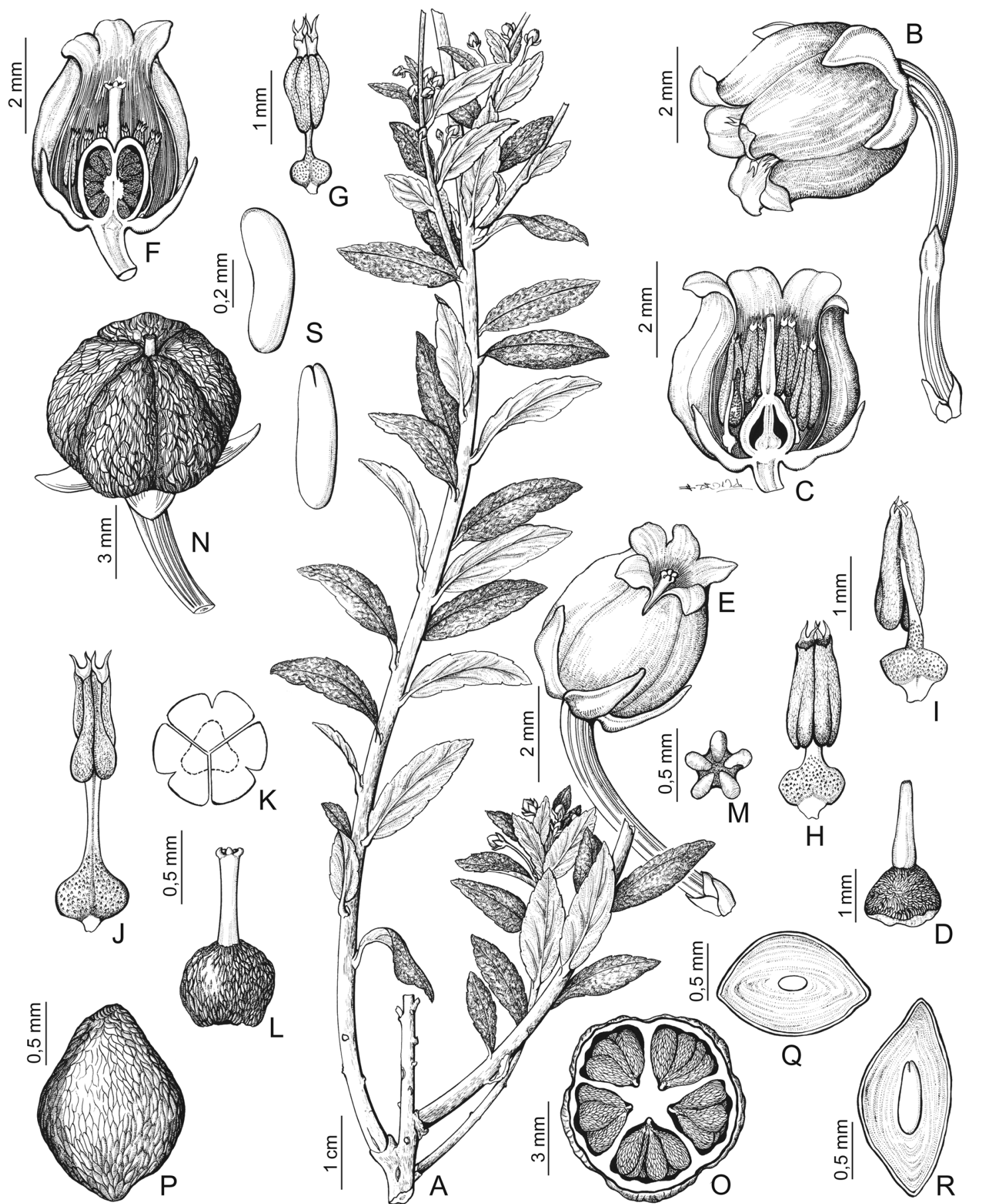
Pernettya breviflora Phil., Linnaea 29: 12. 1858. TIPO: Chile. Cordillera de Santiago, 1856, F. Germain s.n, (lectotipo SGO 4158!, designado aquí; isolectotipos SGO 53717!, SGO 41823!, SGO 41831!).

Arbustos de 4-6 (8) cm de alto. Tallos erguidos o procumbentes y menos densamente foliosos que en la variedad tipo. Hojas no imbricadas, de 3-4 (5) × 2,5 mm, a veces casi lineares. Fruto de color blanco.

Distribución geográfica. Variedad nativa de Chile y de la Argentina, donde se encuentra en las provincias de Chubut, Mendoza, Neuquén, Río Negro y Santa Cruz.

Observación. La imagen con código de barras 00715736 en el herbario P muestra un ejemplar etiquetado como "isotipo de Pernettya leucocarpa", pero está coleccionado por C. Gay, no por E. F. Poeppig.

\section{Material representativo examinado}

ARGENTINA. Chubut. Depto. Languiñeo, lago Paz, Soriano 4609 (BAA). Mendoza. Depto. Malargüe, paso Pehuenches, sobre la frontera con Chile, Boelcke et al. 10389 (BAB, SI). Neuquén. Depto. Aluminé, Villa Pehuenia, cerro Batea Mahuida, Zuloaga et al. 14876 (SI). Río Negro. Depto. Bariloche, El Bolsón, subida al cerro Piltriquitrón, Zuloaga et al. 13867 (SI). Santa Cruz. Depto. Lago Argentino, laguna del ventisquero, valle del río Fitz-Roy, Sleumer 1440 (LIL).

\section{Var. pumila}

Andromeda empetrifolia Lam., Encycl. 1(1): 155. 1783. Pernettya empetrifolia (Lam.) Gaudich., Ann. Sci. Nat. (Paris) 5: 102. 1825, nom. superfl. Pernettya pumila (L.f.) Hook. var. empetrifolia (Lam.) Hook.f., Fl. Antarct. 2: 192.1898. TIPO: Chile. Magellan., 1767, $P$. Commerson s.n. (isotipos MPU cb 012418!, MPU cb 012419!, MPU cb 012420!, P cb 00715739!, P cb 00715740!, P cb 00715741!, $\mathrm{P}$ cb 00715742!).
Pernettya crassifolia Phil., Linnea 29: 10. 1858. Pernnetya pumila var. crassifolia (Phil.) Sleumer, Lilloa 25: 539. 1952. Gaultheria pumila var. crassifolia (Phil.) D.J. Middleton, Edinburgh. J. Bot. 47(3): 298.1990. TIPO: Chile. Volcán Osorno (monte "Pichijuan"), R. A. Philippi 85 (holotipo SGO 53664!).

Pernettya trinervia Gand., Bull. Soc. Bot. France 60: 24. 1913. TIPO. Argentina. Islas Malvinas, Stanley Harbour, C. Skottsberg 17 (S, no visto).

Arbustos de 2-3 cm de altura. Tallos delgados, rastreros a procumbentes. Hojas de 2-3 x 1,5 mm. Fruto de color rosado; pedúnculo del fruto cuatro veces más largo que las hojas.

Iconografía. Sleumer, H. \& P. M. Hermann. 1999. 8(6): 14, fig. 9.

Nombres vulgares. "Chaura", "shal", "shan ámain".

Distribución y hábitat. Nativa de Chile y la Argentina, donde se encuentra entre las provincias de Río Negro y Tierra del Fuego. Crece en sitios abiertos y húmedos en la alta montaña y en la estepa patagónica.

Observaciones. Teillier \& Escobar (2013), consideraron a Pernettya crassifolia como eventual sinónimo de Gaultheria pumila var. leucocarpa, pero un examen más detallado de los especímenes inducen a colocarla en sinonimia de la variedad tipo.

\section{Material representativo examinado}

ARGENTINA. Chubut. Depto. Futaleufú, lago Menéndez, Forcone 1094 (CORD). Neuquén. Depto. Ñorquín, Copahue, Chiapella 1834 (CORD, CTES, SI). Río Negro. Depto. Bariloche, cerro Catedral, Villamil 3027 ((SI). Santa Cruz. Depto. Güer Aike, Río Turbio, estancia Stag River, meseta de La Torre, ladera superior sur, Boelcke et al. 16761 (BAB). Tierra del Fuego, Antártida e Islas de Atlántico Sur. Depto. Ushuaia, isla de los Estados, Puerto Cook, Nicora 7305 (BAB). 
Gaultheria tenuifolia (Phil.) Sleumer, Notizbl. Bot. Gart. Berlin-Dahlem 13: 207. 1936. Pernettya tenuifolia Phil., Linnaea 29: 10. 1858. TIPO: Chile. In provincia Valdivia, R. A. Philippi s.n., (foto Serie Field Mus. Neg. nro. 4599 ex B ${ }^{\dagger}$ ).

Pernettya elegans Phil., Linnaea 33: 172. 1864. Gaultheria elegans (Phil.) Reiche, Anales Univ. Chile 117: 498. 1905. Gaultheria tenuifolia (Phil.) Sleumer var. elegans (Phil.) Kausel, Revista Univ. (Santiago) 34: 174. 1949. TIPO: Chile. Pie de la cordillera de Ranco, R. Pearce s.n. (lectotipo SGO 41777!, designado aquí; isolectotipo SGO 53704!).

Pernettya reticulata Phil., Anales Univ. Chile. 43: 507. 1873. TIPO: Chile. Nahuelbuta, G. Volkmann s.n. (lectotipo, SGO 53708!, designado aquí; isolectotipo SGO 41837!).

Gaultheria salicifolia Phil., Anales Univ. Chile 90: 192. 1895. TIPO: Chile. Habitat prope Constitucion, 1881, R. Azo-Cart s.n. (lectotipo SGO 53746!, designado aquí; isolectotipo SGO 53747!); existe, además, una fotografía de la Serie Field Museum (Neg. nro. 4760) de un isotipo destruido en Berlín.

Pernettya promaucana Phil., Anales Univ. Chile 90: 195. 1895; Gaultheria tenuifolia var. promaucana (Phil.) Kausel, Revista Univ. (Santiago) 34: 175. 1949. TIPO: Chile. Constitución, R. Azo-Cart s.n. (holotipo SGO 53703!).

Gaultheria myrtilloides Hook. \& Arn. var. major Hook. et Arn., J. Bot. (Hooker) 1: 281. 1834 TIPO: Chile: "Ravines between Valdivia and Osorno, Bridges 565 (K cb 000641632 !).

Arbustos dioicos de hasta $2,5 \mathrm{~m}$ de altura; tallos jóvenes angulosos, comprimidos y glabros. Hojas pecioladas, coriáceas, glabras y lustrosas; lámina linear-elíptica hasta oblongoelíptica, de (20) 23-35 (50) × 3-9 (11) mm, débilmente falcada y terminada en un mucrón agudo, margen con 6-7(8) dientes pequeños y redondeados, más o menos profundos a ambos lados, a veces casi entero; vena central prominente en el envés. Flores solitarias, blancas a rosadas, axilares y nutantes, pedicelo de $10 \mathrm{~mm}$, con varias brácteas pequeñas y 2-4 bractéolas en la base; cáliz profundamente 5-partido, lóbulos de más o menos $1,8 \mathrm{~mm}$, triangulares y agudos; corola de más o menos $4 \mathrm{~mm}$, urceolado-cilíndrica; flores estaminadas con 10 estambres, anteras fértiles; flores pistiladas, con 10 estambres y anteras estériles; gineceo con ovario de 1,2-1,5 mm. Fruto una cápsula de 4-5 $\mathrm{mm}$ diámetro, subcoriácea, rodeada casi enteramente por los lóbulos del cáliz, éstos carnosos y de color castaño-rojizo en su madurez.

Iconografía. Sleumer, H. \& P. M. Hermann. 1999. 8(6): 9, fig. 6.

Distribución y hábitat. Especie nativa de Chile y de la Argentina donde habita en las provincias de Neuquén y Río Negro. Crece en los bosques de Nothofagus obliqua (Mirb.) Oerst. ("roble pellín") y $N$. dombeyi.

\section{Material representativo examinado}

ARGENTINA. Río Negro. Depto. Bariloche, a orillas del arroyo Casa de Piedra, Villamil 2318 (BBB, SI).

Gaylussacia Kunth, Nov. Gen. Sp. (quarto ed.): 275; pl. 257. 1819. ESPECIE TIPO: Gaylussacia buxifolia Kunth.

Arbustos o subarbustos erectos, densamente hojosos, caducifolios. Inflorescencias en racimos axilares, paucifloros. Flores pequeñas, perfectas; cáliz formado por 5 sépalos connados, adnatos al ovario para formar un hipanto persistente en el fruto; pétalos 4-5, casi completamente unidos, blanquecino-verdosos a blanco-rosáceos, corola urceolada, acampanada, brevemente 5-lobada; estambres 10, inclusos, filamentos rectos, aplanados; anteras subsagitadas, bífidas, dehiscentes por poros terminales angostos; gineceo 5-10-carpelar; ovario ínfero pseudo 10-locular, con 5 lóculos 2-ovulados, divididos por septos incompletos; estigma capitado. Fruto drupáceo ovoide a globoso, carnoso, con 10 pirenos monospermos. Número básico de cromosomas $x=12$. 

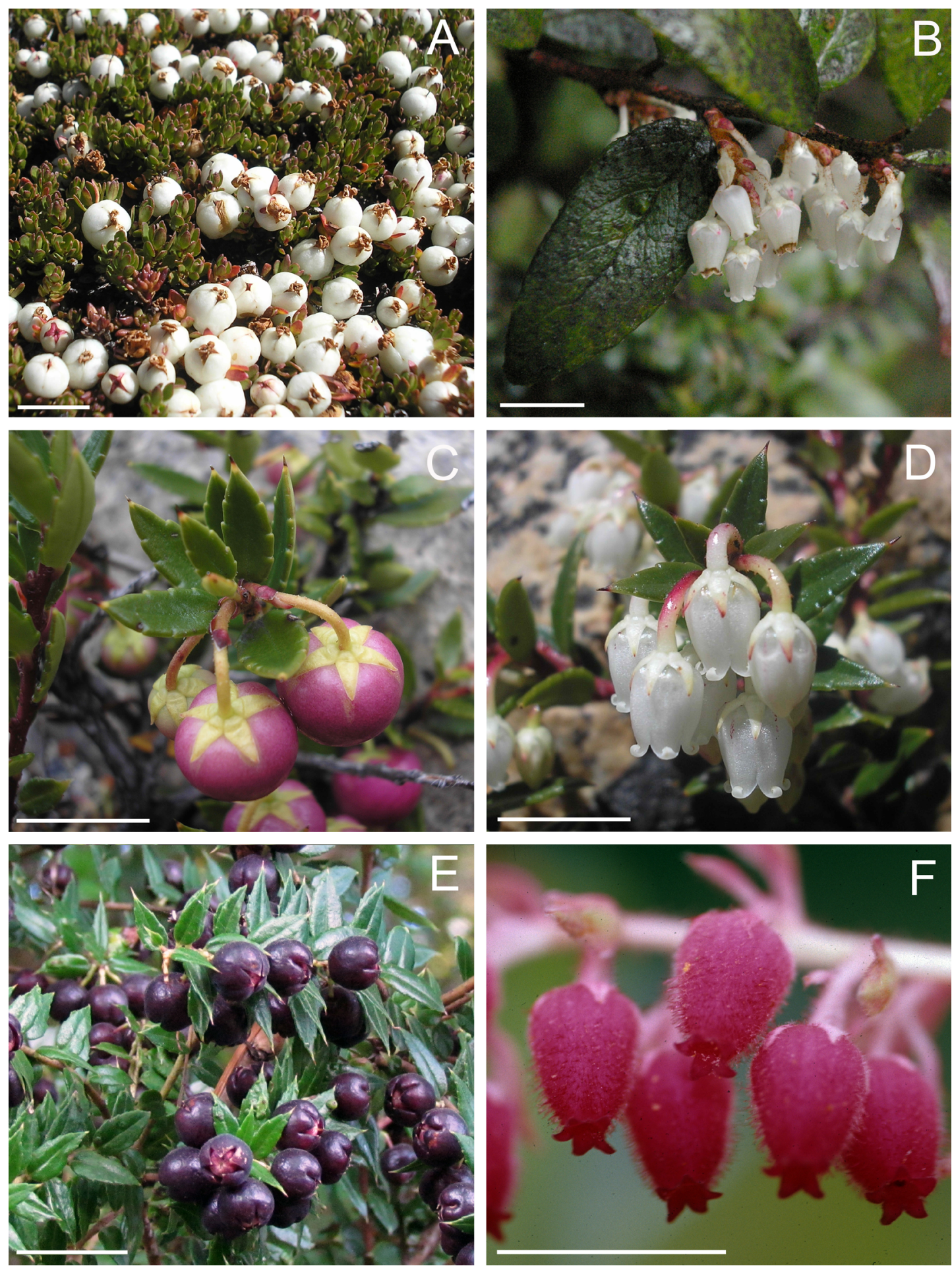

Fig. 4. A, Gaultheria caespitosa. B, Gaultheria insana. C-D, Gaultheria mucronata. E, Gaultheria phillyreifolia. F, Gaultheria erecta. Fotografías: A, C y D de M. L. Iribarren; B y E de S. Teillier; F de O. Morrone. Las barras blancas al pie de cada fotografía representan $1 \mathrm{~cm}$. Figura en color en la versión en línea http:// www.ojs.darwin.edu.ar/index.php/darwiniana/article/view/845/1159 
Género disyunto entre Norte y Sud América, con 45-50 especies. En su mayor parte, las especies (37) habitan en Sudamérica, en especial en el sudeste de Brasil; cuatro son andinas y crecen desde Ecuador hasta Bolivia y una de ellas llega al norte de la Argentina.

El número de especies que habita en América del Norte es controvertido y varía según los autores entre cuatro con numerosas variedades (Floyd, 2002) a 10 (Tucker, 2009). Sleumer (1967) reconoció en el género tres secciones las que son desestimadas por Floyd (2002) a partir de datos moleculares; a la par Floyd (l.c.) propone que el origen del género sería norteamericano a pesar de la gran diversidad que exhibe en Sudamérica.

Gaylussacia cardenasii A.C. Sm., J. Wash. Acad. Sci. 43: 206. 1953. TIPO: Bolivia. Santa Cruz, Samaipata, El Fuerte, 1700 m s.m., XI 1950, M. Cárdenas 4643 (holotipo US cb 00116881 !; isotipo L cb 0007183!).

Arbustos de 0,3-0,7 (3) $\mathrm{m}$ de alto, muy ramosos. Ramas jóvenes pubérulo-tomentosas, indumento glandular blanquecino, con glándulas subsésiles de 0,5 $\mathrm{mm}$; ramas adultas glabrescentes o glabras. Hojas oblongas, de 2,5-5 cm long. ${ }^{x}$ 7-10 mm lat., glabras, provistas de una glándula en el ápice, las jóvenes copiosamente amarilloglandulosas en ambas caras, las adultas glabrescentes a glabras ya que las glándulas no se perciben. Inflorescencia en racimos axilares 2-8 (10)-floros, de 2-3 cm, glabrescentes. Flores perfectas; cáliz acampanado, de 3-4 mm, pubescente, lóbulos triangulares, algo inflexos en el fruto; corola blanca o rosada de 5-6 $\mathrm{mm}$. Fruto globoso de 4-5 mm de diám.

Iconografía. Cabrera, A. L. 1983. 13(8): 11, fig. 5 .

Distribución y hábitat. Especie nativa del sur de Bolivia y noroeste de la Argentina, donde es poco frecuente; habita en campos de altura y laderas con pastizales entre $1000 \mathrm{y}$ 3000 m s.m.
Observación. Es la única de las especies andinas del género que tiene indumento glandular, siendo las glándulas subsésiles excepto en el tubo del cáliz, carácter que comparte con un grupo de entidades brasileñas.

\section{Material representativo examinado}

ARGENTINA. Salta. Depto. Santa Victoria, Ruta Provincial 19, $10 \mathrm{~km}$ de Los Toldos a Lipeo, Morrone et al. 3876 (SI).

Lebetanthus Endl., Gen. P1.: 1411, 1458. 1841, nom. cons. ESPECIE TIPO: Lebetanthus americanus (Hook.) Endl. ex Hook. (=Prionotes americana Hook.), typ. cons.

Arbustos o subarbustos trepadores, ramificados. Tallos jóvenes surcados. Hojas alternas, brevemente pecioladas, coriáceas, subelípticas, agudas en el ápice. Flores solitarias, axilares, perfectas, péndulas; pedicelo casi tan largo como la corola, cubierto por bractéolas imbricadas insertas a distintos niveles; sépalos lobados, agudos en el ápice; corola suburceolada, 5-lobada, lóbulos breves; androceo 5-mero, filamentos libres; escamas nectaríferas 5; gineceo con ovario 5-locular, estilo recto y estigma capitado. Fruto una cápsula 5 -valvada, estilo persistente a la madurez. Semillas fusiformes.

Género monotípico, endémico en Sudamérica austral.

Lebetanthus myrsinites (Lam.) Dusén, Svenska Exped. Magellans. 3 (5): 139. 1901. Andromeda myrsinites Lam., Encycl. 1: 155. 1783. Pernettya myrsinites (Lam.) G. Don, Gen. Hist. 3: 836. 1834. Prionotes myrsinites (Lam.) Skottsb., Kongl. Svenska Vetensk. Acad. Handl., n.s. 56(5): 284. 1916. Lebetanthus myrsinites (Lam.) Dusén, Rep. Princeton Univ. Exp. Patagonia 1896-1899, Botany 8(2): 649. 1905, comb. superfl. TIPO: Argentina/Chile?. "Dans les bois montagneux des terres Magellaniques", XII 1767, P. Commerson s.n. (holotipo P-LAM; isotipos L cb 0006498!, MA cb 248298!, MPU cb 012416!, P cb 00760720!, P cb 00760721!, P cb 00760722!). 
Arbutus microphylla G. Forst., Commentat. Soc. Regiae Sci. Gott. 9: 32. 1789. Gaultheria microphylla (G. Forst.) Hook. f., Fl. Antarct. 2: 237. 1846. Pernettya hookeri Nied., Bot. Jahrb. Syst. 11: 172, 190, 224. 1889. TIPO: Tierra del Fuego, Forster (BM, K, M cb 0164781!) (cfr. B. L. Burtt, Kew Bull. 1934: 401-402).

Prionotes americana Hook., Icon. Pl. 1: tab. 30. 1836. Lebetanthus americanus (Hook.) Endl. ex Hook.f., Fl. Antarct. 2: 327.1846. SINTIPOS: [Argentina]. "Cape Horn. Foster. Staten-Land, near Terra del Fuego. Mr. Reynolds (n. 24 and 36)" (no vistos).

Arbustos o subarbustos $c a .50 \mathrm{~cm}$ de altura, trepadores, muy ramificados, con las ramas radicantes. Tallos ascendentes esparcidamente pilosos, los jóvenes surcados. Hojas ovadas, de 3-7 mm, el borde 4-8-dentado, con un pelo capitado en la axila de cada diente, agudas en el ápice. Flores con pedicelo de $2-4 \mathrm{~mm}$, cubierto por (8) 10-18 bractéolas estrechamente ovadas, solitarias, axilares; sépalos 2,5-3,5 mm; corola de 4-6 $\mathrm{mm}$, blanquecina a rosada; estambres con filamentos de la longitud de la corola; ovario globoso, con 5-8 óvulos colgantes por lóculo; escamas nectaríferas 5, óvulos ca. 10 en cada lóculo, estigma discoide. Fruto elipsoide, de 2-3 mm, con 1-5 semillas por lóculo.

Iconografía. Arroyo, S. 1975. Lebetanthus, género austroamericano de Epacridaceae y sus diferencias con el género Prionotes de Tasmania. Darwiniana 19: 318, fig. 2.

Distribución y hábitat. Especie de Chile y la Argentina, donde habita en Tierra del Fuego y en la isla de los Estados. Forma parte del estrato arbustivo de los bosques andino-patagónicos, siendo muy abundante en aquellos caracterizados por el "guindo" (Nothofagus betuloides). Por su particular forma biológica crece formando una densa maraña alrededor de los troncos (Arroyo, 1975).

\section{Material representativo examinado}

ARGENTINA. Tierra del Fuego, Antártida

e Islas de Atlántico Sur. Depto. Ushuaia, Isla de los Estados, Puerto Cook, Nicora 7336 (BAA, BAB, RNG).
Vaccinium L., Sp. Pl. 1: 349. 1753. ESPECIE TIPO: Vaccinium uliginosum L., lectotipo designado por S. P. Vander Kloet, Taxon 30: 647. 1981.

Arbustos, lianas o árboles bajos, achaparrados, hojosos. Hojas alternas, coriáceas, pecioladas, margen entero o algo aserrado. Inflorescencias axilares, en racimos o fascículos, provistas de brácteas y bractéolas persistentes o más o menos caducas. Flores 4-5 (6)-meras; cáliz 4 ó 5 lobado; corola urceolado-campanulada, 4-5 lobada o dentada; androceo con 8-10 estambres, usualmente inclusos, anteras apendiculadas o no, con dehiscencia por poros apicales; disco anular; gineceo con ovario 4-5 (10) locular con falsos septos. Fruto carnoso, globoso, con varias semillas.

Género cosmopolita, con $c a .140$ especies que habitan en todos los continentes -excepto Australiay son particularmente abundantes en Asia oriental. En Sudamérica viven alrededor de 20 especies, de las que sólo una llega al noroeste argentino.

Vaccinium floribundum Kunth, Nov. Gen. Sp. (quarto ed.) 3: 266, tab. 251. 1818[1819]. TIPO: Perú. "Crescit in montanis Peruviae, prope Caxamarca, alt. 1700 hex. Floret Augusto", $A$. J. A. Bonpland s.n. (holotipo P cb 00670968!).

Vaccinium ramosissimum Dunal, Prodr. 7: 751. 1839. Vaccinium floribundum var. ramosissimum (Dunal) Sleumer, Notizbl. Bot. Gart. BerlinDahlem 13(116): 131. 1936. TIPO: Perú, $J$. A. Pavón s.n. (holotipo G-DC cb 00135244!; isotipo $\mathrm{P}$ cb 00649600!).

Arbustos de porte variado, a veces compactos, que alcanzan hasta 2-3 $\mathrm{m}$ de altura, o bien subarbustos procumbentes o escandentes, enanos y postrados, no mayores de $25-30 \mathrm{~cm}$. Ramas jóvenes pubescentes, las adultas glabras, rugosas. Hojas alternas, brevemente pecioladas; lámina lanceolada, de 1-2 cm, coriáceas, con diminutos pelos glandulares, en la cara abaxial, margen aserrado-dentado, cada diente terminado en un diminuto pelo glandular, presentes también en la cara abaxial. Inflorescencia en racimos axilares (3) 5-6 (10)-floros, hasta $1,5 \mathrm{~cm}$; pedicelo con 
bractéolas en la base. Flores 4-5-meras, hasta $8 \mathrm{~mm}$; cáliz ca. 3-4 mm; hipanto cilíndrico, ca. 1,3-2 mm; corola cilíndrica a acampanada, blancorosada a rojiza, con 4-5 lóbulos redondeados, breves, ca. 1,5 mm;estambres 8-10 insertos en la base del tubo corolino, anteras con o sin 2 cortas aristas dorsales, dehiscentes por poros apicales; ovario ínfero 4-5-locular, con varios óvulos por lóculo. Fruto en baya globosa, de $5-8 \mathrm{~mm}$ de diám., violácea a negro-azulada, a veces glauca, por su cubierta cerosa.

Iconografía. Cabrera, A. L. 1983. 13(8): 13, fig. 6 (sub Vaccinium floribundum var. ramosissimum).

Nombres vulgares. "Manzanilla del cerro", "mortiño", "raspadura quemado" (Ecuador); "macha-macha" (Bolivia).

Usos. El fruto se consume fresco o cocido en mermeladas o bien como uno de los ingredientes de la "colada morada", bebida popular en Ecuador. Sus aplicaciones dentro de la cultura popular son múltiples ya que se lo considera por sus propiedades antioxidantes, como coadyuvante nutrimental, colorante alimentario entre otras aplicaciones (Coba et al. 2012). El leño se utiliza como combustible $\mathrm{y}$, en apariencia, la planta sería resistente al fuego, rebrotando con vigor (Luteyn, 1996).

Distribución y hábitat. Centroamérica (Costa Rica) y Sudamérica andina: Venezuela, Colombia, Ecuador, Perú y Bolivia hasta el noroeste de la Argentina. En selvas montanas bajas, secas o húmedas, a 1400-4350 m s.m.

\section{Material representativo examinado}

ARGENTINA. Salta. Depto. Santa Victoria, Toldos, cuesta de San José, cerca del Abra, Sleumer 3831 (LIL, SI).

\section{AGRADECIMIENTOS}

A los curadores de los herbarios consultados, a Myriam Cuasolo por su eficaz asistencia en la búsqueda bibliográfica, a Andrea Ugarte por la ilustración de Gaultheria marticorenae y a Francisco Rojas por la ilustración de Agarista paraguayensis.

\section{BIBLIOGRAFIA}

Arroyo, S. 1975. Lebetanthus, género austroamericano de Epacridaceae y sus diferencias con el género Prionotes de Tasmania. Darwiniana 19(2/4): 312-330.

Arroyo, S. 1999. Epacridaceae, en M. E. Correa (dir.), Flora Patagónica, Colección Cientifica del Instituto Nacional de Tecnología Agropecuaria 8(4): 16-17.

Cabrera, A. L. 1983. Ericaceae Juss., en A. L. Cabrera (dir.), Flora de la Provincia de Jujuy, Colección Científica del Instituto Nacional de Tecnología Agropecuaria 13(8): 2-12.

Cambi, N. V. \& P. M. Hermann. 1989. Critical studies on the sexuality of southern Argentinian Ericaceae. Sexual Plant Reproduction 2: 142-149.

Coba, P.; D. Coronel, K. Verdugo, M. Paredes, E. Yugsi \& L. Huachi. 2012. Estudio etnobotánico del mortiño (Vaccinium floribundum) como alimento ancestral y potencial alimento funcional. La Granja 16(2): 5-13.

Floyd, J. W. 2002. Phylogenetic and Biogeographic Patterns in Gaylussacia (Ericaceae) based on Morphological, Nuclear DNA, and Chloroplast DNA Variation, Systematic Botany 27: 99-115.

Gunckel, H. 1972. Plantas chilenas descritas como nuevas por Juan Ignacio Molina y sus concordancias con la nomenclatura botánica actual. Noticiario Mensual del Museo Nacional de Historia Natural, Chile 197: 3-11.

Hermann, P. M. \& V. N. Cambi. 1992. Nuevos datos sobre la sexualidad de Gaultheria caespitosa Poepp. \& Endl. (Ericaceae). Parodiana 7: 83-90.

Hermann, P. M. \& V. N. Cambi. 2006. Gaultheria nubigena (Ericaceae), una especie rara en la Argentina. Boletín de la Sociedad Argentina de Botánica 41(3-4): 317 - 322.

IPNI, The International Plant Names Index, disponible en: http://www.ipni.org (consulta julio-diciembre 2018).

JSTOR Global Plants, disponible en: https://www.plants.jstor. org [consulta junio-diciembre 2018].

Judd, W. S. \& P. M. Hermann, 1990. Circumscription of Agarista boliviensis (Ericaceae). Sida 14: 263-266.

Kausel, E. 1949. Comentario sobre las ericáceas y epacridáceas chilenas. Revista Universitaria (Santiago). 34(I):155-178.

Luteyn, J. L. 1996. Ericaceae, en: G. Harling \& L. A. Andersson (eds.), Flora of Ecuador 54: 1-404.

Middleton, D. J. \& C. C. Wilcock. 1990. A critical examination of the status of Pernettya as a genus distinct from Gaultheria. Edinburgh Journal of Botany 47(3): 291-301.

Read, D. J. 1996. The structure and function of the ericoid mycorrhizal root. Annals of Botany 77: 365-374.

Reiche, K. 1905. Estudios críticos sobre la flora de Chile. Ericaceae. Anales de la Universidad de Chile 117: 487-500. 
Sleumer, H. 1934. Ericaceae americanae novae vel minus cognitae. Notizblatt des Botanischen Gartens und Museums zu Berlin-Dahlem 112: 119-140.

Sleumer, H. 1935. Ericaceae americanae novae vel minus cognitae II. Notizblatt des Botanischen Gartens und Museums zu Berlin-Dahlem 12(113): 277-294.

Sleumer, H. 1951. Las Ericáceas argentinas. Lilloa 25: 515-556.

Sleumer, H. 1959. Studien Über die Gattung Leucothoë D. Don, Botanische Jahrbücher für Systematik 78: 435-480.

Sleumer, H. 1967. Die Gattung Gaylussacia H.B.K. Botanische Jahrbucher fur Systematik 86: 309-384.

Sleumer, H. 1985. Taxonomy of the genus Pernettya Gaud. (Ericaceae). Botanische Jahrbücher für Systematik 105(4): 449-480.

Sleumer, H. \& P. M. Hermann, 1999. Ericaceae Juss., en M. N. Correa (ed.), Flora Patagónica, Colección Científica del Instituto Nacional de Tecnología Agropecuaria 8(6): 1-15.
Stevens, P. F.; J. Luteyn, E. G. H. Oliver, T. L. Bell, E. A. Brown, R. K. Crowden, A. S. George, G. J. Jordan, P. Ladd, K. Lemson, C. B. McLean, Y. Menadue, J. S. Pate, H. M. Stace \& C. M. Weiller. 2004. Ericaceae, en K. Kubitski, (ed.) The Families and Genera of Vascular Plants 6: 145194. Springer-Verlag, Berlin.

Teillier, S. \& F. Escobar. 2013. Revisión del género Gaultheria L. (Ericaceae) en Chile. Gayana, Botánica 70(1): 136-153.

Thiers, B. [permanentemente actualizado, consulta 2018] Index Herbariorum: a global directory of public herbaria and associated staff. New York Botanical Garden's Virtual Herbarium, http://sweetgum.nybg.org/ih

Tropicos ${ }^{\circledR}$, Missouri Botanical Garden. Disponible en: http:// www.tropicos.org (consulta julio-diciembre 2018)

Tucker, G. 2009. Ericaceae, en Flora of North America Editorial Committee (ed.), Flora of North America 8: 364-504.

Urcelay, C. 2002. Co-occurrence of three fungal root symbionts in Gaultheria poeppigii DC. in Central Argentina. Mycorrhiza 12: 89-92. 